\title{
A delayed differentiation multiproduct model with the outsourcing of common parts, overtime strategy for end products, and quality reassurance
}

\author{
Singa Wang Chiu ${ }^{\mathrm{a}}$, Victoria Chiu ${ }^{\mathrm{b}}$, Ming-Hon Hwang ${ }^{\mathrm{c}}$ and Yuan-Shyi Peter Chiu ${ }^{\mathrm{d}}$
}

${ }^{a}$ Department of Business Administration, Chaoyang University of Technology, Taichung 413, Taiwan

${ }^{b}$ Department of Accounting, Finance and Law, The State University of New York, Oswego, NY 13126, USA

${ }^{c}$ Department of Marketing \& Logistics Management, Chaoyang University of Technology, Taiwan

${ }^{d}$ Department of Industrial Engineering \& Management, Chaoyang University of Technology, Taichung, Taiwan

\begin{tabular}{l}
\hline C H R O N I C L E \\
\hline Article history: \\
Received December 102020 \\
Received in Revised Format \\
December 282020 \\
Accepted December 302020 \\
Available online \\
January, 42021 \\
\hline Keywords: \\
Multiproduct batch manufacturing \\
Delayed differentiation \\
Overtime \\
Outsourcing \\
Quality reassurance
\end{tabular}

\section{Introduction}

This study presents a two-stage delayed-differentiation multiproduct model that considers the outsourcing options for common parts, quality reassurance, and overtime strategy for end products to assist in making fabrication runtime decisions that are cost-effective. Production planners always seek a better multiproduct manufacturing scheme such as the postponement (or delayed-differentiation) policy to reduce operation uptime and total relevant expenses, especially when dealing with end products with common components. Van Hoek (1999) conducted interviews from various industries, including clothing, electronics, food, and automotive manufacturers in Germany, Belgium, and the Netherlands, to explore the challenge and advantage of the postponement/reconfiguration of the industrial supply chains. Their results could facilitate managerial decision-making. Blecker and Abdelkafi (2006) analyzed mass customization systems' complexity and variety to offer managerial insights to deal with potential problems cause by the complexity and variety in the mass customization

* Corresponding author Tel.: +886 4-23323000 (x5205)

E-mail: hwangmh@cyut.edu.tw (M.-H. Hwang)

2021 Growing Science Ltd.

doi: $10.5267 / j$.ijiec.2021.1.001 
environments. Seth and Panigrahi (2015) used a case study to investigate the effect of packaging postponement policy on response time reduction in supply chains. Their results demonstrated that the strategy of packaging postponement could improve product proliferation, order response time, and competitive advantage through empirical evaluation of real data. Additional works (Jabbarzadeh et al., 2019; Cerdá et al., 2020; Chakraborty et al., 2020; Chiu et al., 2020a) explored the influence of diverse delayed-differentiation or postponement strategies on manufacturing firms, corporation management, and various supply-chain systems. To produce nonconforming products is inevitable in real manufacturing environments. Production managers are responsible for identifying and reworking/scrapping these faulty items to reassure the client's expected quality. Kim et al. (2000) examined a repairable-item multi-echelon system with spares. The researchers proposed an optimal algorithm to determine the spare stock level for the proposed problem and demonstrated their algorithm with several examples that have various sizes. Roy et al. (2009) considered a deterministic single- product fabricationremanufacturing system in a fuzzy environment. Both used-products from the clients and the defective-items from the fabrication process are collected and remanufactured. Upon accomplished the remanufactured items, they are treated as acceptable/ fresh stocks to meet the client's requirements. The fuzzy defective production function was assumed and analyzed to derive the total profit of the problem. A few particular situations were examined to validate the results. Sonntag and Kiesmüller (2018) examined a stochastic-demand stock replenishing system with random yield and reworking/disposing of the faulty products. To cope with the stochastic client orders, the authors proposed an optimization model to facilitate production planners' decision making on rework or disposal of the defective items. Additional works (Arun et al., 2019; Larkin \& Privalov, 2019; Jimmy et al., 2020; Mabude et al., 2020; Uniyal et al., 2020) also investigated the impact of various product quality issues on manufacturing systems, fabrication planning, and supply-chain systems.

To effectively reduce stage one's uptime/utilization for the common components effectively, this study adopts a partial outsourcing option. Kamien et al. (1989) proposed a two-stage game approach to explore the impact of outsourcing production on the rival's competition for a contract or a market. In stage one, the researchers studied the battle of a contract/market price. In stage two, they examine the effect of situations of possible subcontracting of each other's production on their competition. Different scenarios of winner and loser in-between stages were assumed and investigated to obtain the managerial insights on the subcontracting and bargaining influence on the firms. Van Mieghem (1999) analyzed a competitive investment game considering outsourcing to improve a firm's financial performance and enhance its system coordination. Two parties, namely the producer and outsourcer, were involved in meeting their uncertain demands, fabrication, and sales with their capacity investments levels. The authors examined three distinct subcontracting scenarios in terms of price and variable contractcontents to explore the effect of variations in subcontracting investment scenarios on a manufacturer's cost, production, and profit. Nachiappan et al. (2008) examined a single-producer multi- customers vendor-managed stock system considering outsourcing, focusing on the effect of customers' selling price and producer's offering prices on the proposed supply-chain system. The authors used a mathematical model and a genetic algorithm to resolve this mixed-integer nonlinear problem's optimal sales that maximize the overall profits. Kenyon et al. (2016) studied outsourcing fabrication's impact on a company's production cycle length, lead times, shipment, machine operating effectiveness, client loyalty, and overall performance. The authors analyzed data from various industries' manufacturers to explore the effect of subcontracting fabrication on the firms' operational performance. Their results indicated that fabrication subcontracting decreases substantially on-time delivery and operating machine effectiveness, but it negatively impacts client loyalty. Chiu et al. (2021) built a decision model and employed differential calculus to derive the optimal rotation cycle for a batch multi-item manufacturing problem with delayeddifferentiation, quality assurance, and outsourcing. Recent works (Akkermans et al., 2019; Chiu et al., 2019a,b; Hamers et al., 2019; Chiu et al., 2020b,c; Jha et al., 2020) also studied the impact of different outsourcing strategies on manufacturing firms, corporation management, and various supply-chain systems. Furthermore, this study adopts an overtime strategy to increase stage two's output rate and reduce uptime for fabricating end products. Dellaer and Melo (1998) studied a make-to-order single-product lot-size problem considering stochastic demand, promised order delivery date, backordering, and overtime plan. Four distinct strategies, including three relating to $(\mathrm{s}, \mathrm{S})$ and $(\mathrm{R}, \mathrm{S})$ policies, were examined for these make-to-stock problems to decide each lot-size discipline's performance. Jirjahn (2008) conducted empirical evaluations from German manufacturers' data to explore the elements of overtime and shift work and overtime. The findings of important determinates included (1) the type of tasks, (2) technology, (3) managerial environment, (4) industrial relations, and (5) workforce structure. The researcher concluded that although the similarities exist in most manufacturers' determinants, the differences between shift work and overtime estimations remain. Jaramillo and Erkoc (2017) examined single-resource finite-number-jobs operations under due dates, a regular preempted mode, and limited overtime capacity to minimize their average tardiness and overall overtime costs. A three-stage approach was proposed to achieve the objective. First, the researchers considered a heuristic according to priority discipline and without overtime usage. The second stage incurred overtime option to reduce workload but keep jobs' tardiness unchanged. The last stage considered overtime minimization with possible changing the jobs' tardiness. The researchers compared their heuristics' performance and validated their approach's efficiency with the mixed-integer programming method. Recent works (Aouam \& Kumar, 2019; Lin et al., 2019; Mojeed et al., 2019; Kikuchi et al., 2020; Ouaddi et al., 2020) also investigated the effect of various overtime strategies on corporation management, manufacturing firms, and different supply-chain systems. This study extends Chiu et al.'s (2021) work by implementing an overtime strategy for end product fabrication to reduce stage two's manufacturing uptime further. Since few past research has relating to building a decision model to explicitly explore the impact of dual uptime-reduction strategy and quality reassurance on a delayed-differentiation multiproduct manufacturing system, we would like to fill the research gap. 


\section{The proposed delayed differentiation multiproduct model}

\subsection{Assumption and description}

The proposed delayed differentiation multiproduct model incorporates strategies of outsourcing common parts in stage one, overtime production of end products in stage two, and quality reassurance. This study builds a decision model to represent our studied problem. A Nomenclature (in Appendix A) defines the related symbols used in our study. The assumption and descriptions of the problem are as follows. A two-stage batch multiproduct manufacturing plan is designed to satisfy annual requirements $\lambda_{i}$ of $L$ distinct products (where $i=1,2, \ldots, L$ ). Since the existence of commonality among these multiproduct, stage one fabricates all needed common parts, and stage two produces the finished products. Fig. 1 depicts the stock status of the proposed model featuring outsourcing in stage one, overtime in stage two, and quality reassurance. A constant common part's completion rate $\gamma$ is assumed. Both the common part and end product's fabrication rates $P_{1,0}$ and $P_{1, i}$ depend on $\gamma$. For example, if $\gamma=50 \%$, then both $P_{1,0}$ and $P_{1, i}$ are twice as much as their actual rates in a single-stage manufacturing system. This study employs the rotation cycle time discipline, so the cycle length is as follows:

$$
T_{Z}=t_{1, i}+t_{2, i}+t_{3, i} \quad \text { where } i=0,1,2, \ldots, L
$$

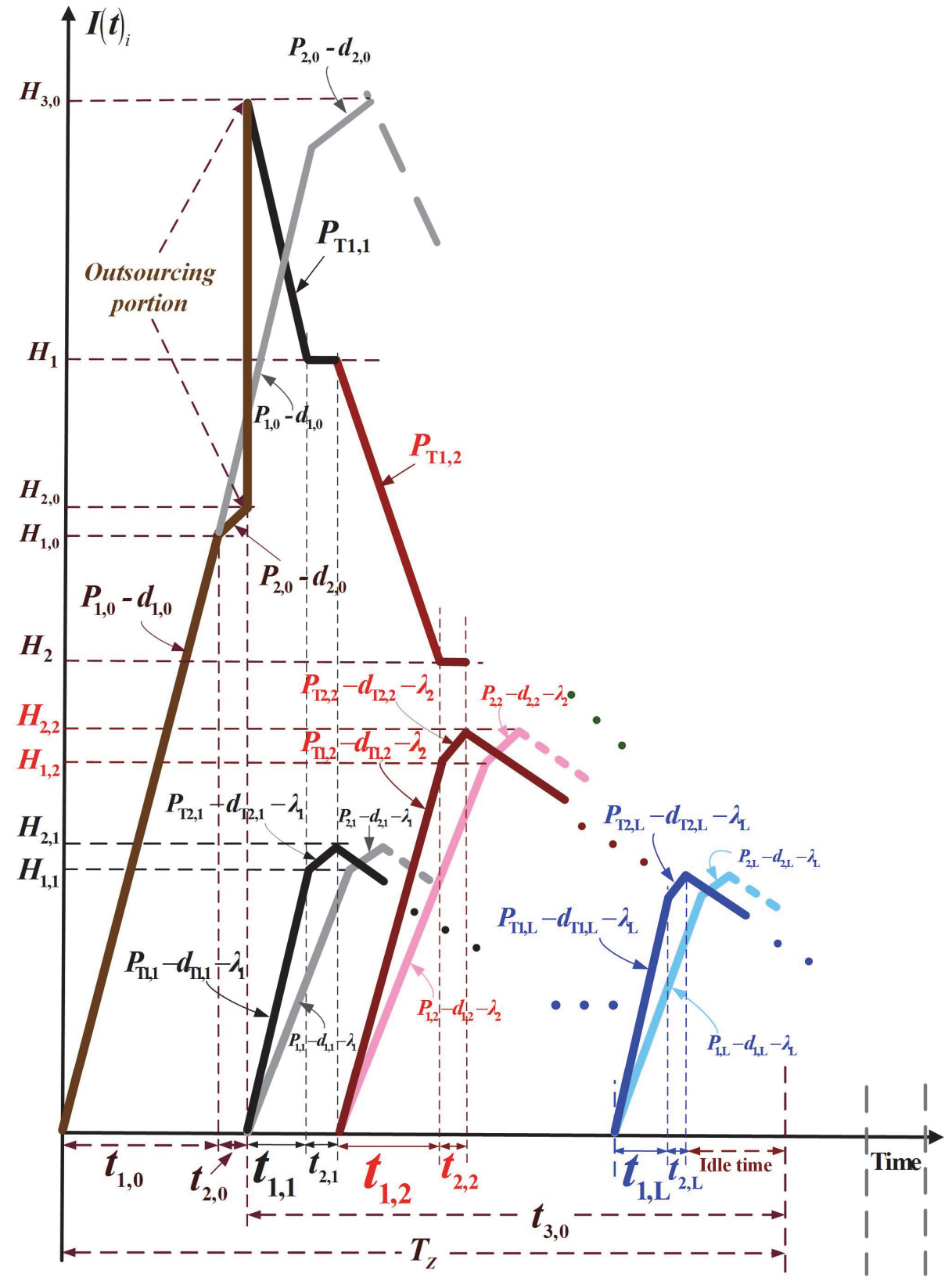

Fig. 1. The inventory status in a replenishment cycle of the proposed model featuring the strategies of outsourcing in stage one, overtime in stage two, and quality reassurance compared to the same model without neither strategies 
To effectively reduce the uptime, we use an external contractor to supply a $\pi_{0}$ portion of the common part's batch in stage one and employ an overtime strategy to produce $L$ different products. We exhibit the following consequent changes in cost parameters and manufacturing/ reworking rates due to implementing outsourcing (see Eqs. (2) and (3)) and overtime strategies (Eqs. (4) to (8)):

$$
\begin{aligned}
& K_{\pi 0}=\left(1+\beta_{1,0}\right) K_{0} \\
& C_{\pi 0}=\left(1+\beta_{2,0}\right) C_{0} \\
& P_{\mathrm{T} 1, i}=\left(1+\alpha_{1, i}\right) P_{1, i} \\
& K_{\mathrm{T}, i}=\left(1+\alpha_{2, i}\right) K_{i} \\
& C_{\mathrm{T}, i}=\left(1+\alpha_{3, i}\right) C_{i} \\
& P_{\mathrm{T} 2, i}=\left(1+\alpha_{1, i}\right) P_{2, i} \\
& C_{\mathrm{T} R, i}=\left(1+\alpha_{3, i}\right) C_{R, i}
\end{aligned}
$$

Production in both stages is assumed imperfect. Random defective rates $x_{0}$ and $x_{i}$ exist in both stages. The scrap portions $\theta_{1,0}$ and $\theta_{1, i}$ are associated with these faulty items. They are identified, and either reworked/repaired or removed. From Fig. 1, we notice that in stage one, when uptime completes the stock accumulates to $H_{1,0}$, and at the end of rework, the stock arrives at $H_{2,0}$. Then, the outsourced items are received as per the predetermined schedule, and the stock level reaches $H_{3,0}$ before stage two. In the second stage, at the end of uptime of the product $i$ (where $i=1,2, \ldots, L$ ), its stock accumulates to $H_{1, i}$, and when rework finishes, the stock arrives at $H_{2, i}$. Then, its inventory starts to deplete under a continuous issuing plan (see Fig. 1). In this study, no shortages are permitted, so the following formulas must hold: in stage- $1,\left(P_{1,0}-d_{1,0}\right)>0$ and in stage-2, $\left(P_{\mathrm{T} 1, i}\right.$ $\left.-d_{\mathrm{T} 1, i}-\lambda_{i}\right)>0$. Meantime, in stage two (see Fig. 1), the common parts' level declines a quantity of $Q_{i}$ (from $\left.H_{3,0}\right)$ to the level of $H_{i}$ at the end of each product's uptime (see also Fig. 2).

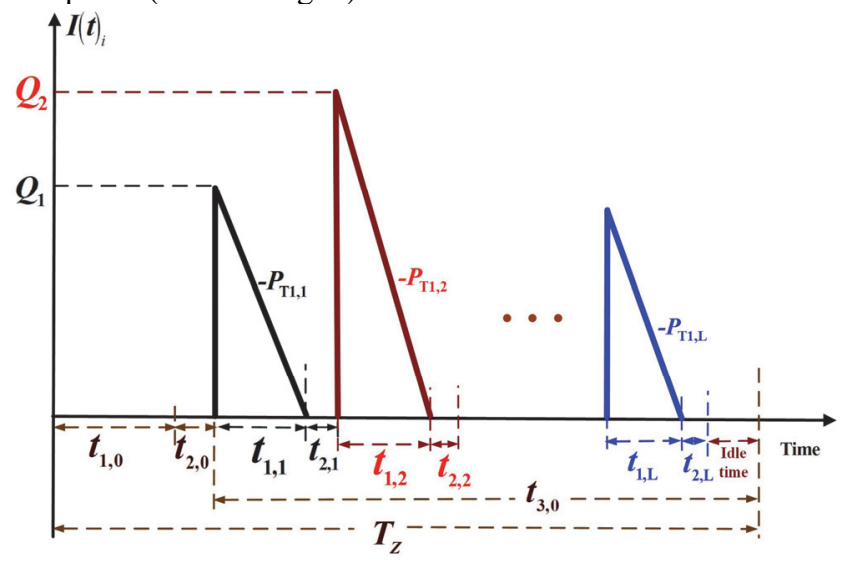

Fig. 2. The status of common parts in stage two of a replenishing cycle

Fig. 3 and Fig. 4 exhibit the inventory status of defective and scrapped items in our proposed model. Fig. 3 shows that when the common part's uptime completes, the defective stock level reaches $\left(d_{1,0} t_{1,0}\right)$. Then, all scrapped items are removed, and the defective stock gradually depletes to zero during the rework time. The same status occurs for end products in stage two.

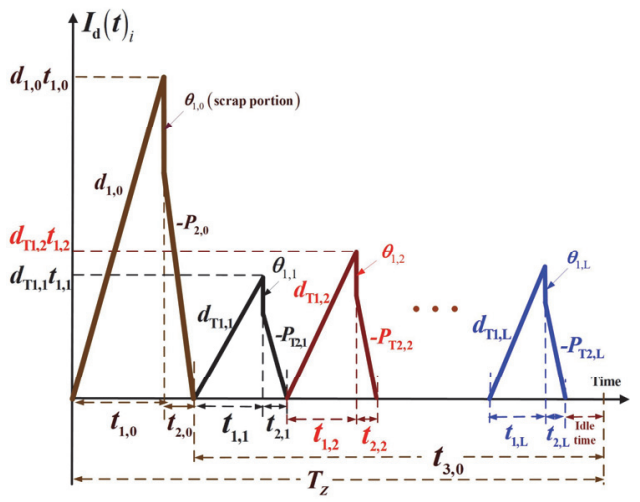

Fig. 3. The status of defective items in a replenishment cycle of our proposed model

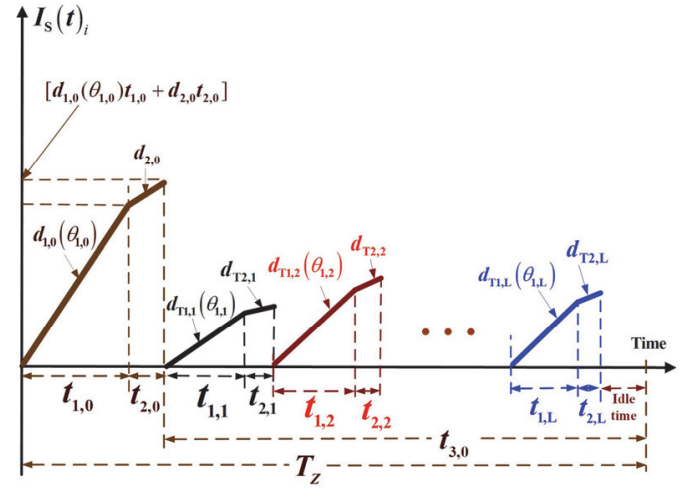

Fig. 4. The status of scraps in a replenishment cycle of our proposed model 
Fig. 4 shows that when stage one' uptime and rework times complete, the scrap stock level reaches its maximum level $\left[d_{1,0}\left(\theta_{1,0}\right) t_{1,0}+d_{2,0} t_{2,0}\right]$. For the end product $i$ in stage two, the maximum level accumulates to $\left[d_{\mathrm{T} 1, i}\left(\theta_{1, i}\right) t_{1, i}+d_{\mathrm{T} 2, i} t_{2, i}\right]$ at the end of uptime and rework times.

\subsection{Formulations of stage two}

We start with formulation of manufacturing $L$ products in stage two. For $i=1,2, \ldots, L$, we can directly observe the following formulas from Figs. 1 through 4 :

$$
\begin{aligned}
& Q_{i}=\frac{\lambda_{i} T_{Z}}{1-\varphi_{i} x_{i}} \\
& t_{1, i}=\frac{Q_{i}}{P_{T 1, i}} \\
& H_{1, i}=\left(P_{T 1, i}-d_{T 1, i}-\lambda_{i}\right) t_{1, i} \\
& H_{2, i}=H_{1, i}+\left(P_{T 2, i}-d_{T 2, i}-\lambda_{i}\right) t_{2, i} \\
& t_{2, i}=\frac{H_{2, i}-H_{1, i}}{P_{T 2, i}-d_{T 2, i}-\lambda_{i}} \\
& t_{3, i}=\frac{H_{2, i}}{\lambda_{i}} \\
& \varphi_{i}=\theta_{1, i}+\left(1-\theta_{1, i}\right) \theta_{2, i}
\end{aligned}
$$

\subsection{Formulations of stage one}

According to the lot size of each end product $i$ (as shown in Eq. (9)), we notice the needed total common parts are as follows:

$$
\sum_{i=1}^{L} Q_{i}=H_{3,0}=\sum_{i=1}^{L} \frac{\lambda_{i} T_{Z}}{1-\varphi_{i} x_{i}}
$$

For stage one, from Figs. 1 through 4, we also can directly observe the following formulas:

$$
\begin{aligned}
& \lambda_{0}=\frac{\sum_{i=1}^{L} Q_{i}}{T_{Z}} \\
& H_{2,0}=\left(1-\pi_{0}\right) H_{3,0}=\left(1-\pi_{0}\right)\left(\sum_{i=1}^{L} Q_{i}\right) \\
& Q_{0}=\frac{H_{2,0}}{1-\varphi_{0} x_{0}} \\
& t_{1,0}=\frac{Q_{0}}{P_{1,0}} \\
& H_{1,0}=\left(P_{1,0}-d_{1,0}\right) t_{1,0} \\
& H_{2,0}=H_{1,0}+\left(P_{2,0}-d_{2,0}\right) t_{2,0} \\
& t_{2,0}=\frac{Q_{0}\left[x_{0}\left(1-\theta_{1,0}\right)\right]}{P_{2,0}}=\frac{H_{2,0}-H_{1,0}}{P_{2,0}-d_{2,0}} \\
& \varphi_{0}=\theta_{1,0}+\left(1-\theta_{1,0}\right) \theta_{2,0} \\
& H_{1}=H_{3,0}-Q_{1}
\end{aligned}
$$




$$
\begin{aligned}
& H_{i}=H_{(i-1)}-Q_{i}, \text { for } i=2,3, \ldots, L \\
& H_{L}=H_{(L-1)}-Q_{L}=0 \\
& T_{Z}=t_{1,0}+t_{2,0}+t_{3,0}
\end{aligned}
$$

\section{System cost function and problem solution}

The total cost per replenishing cycle $T C\left(T_{\mathrm{Z}}\right)$ includes the following expenses incurred in both stages: (a) for stage one, variable and setup costs for outsourcing and in-house fabrication, and the rework, disposal, and inventory holding costs; (b) for stage two: the summation of variable, setup, rework, removal, and stock holding costs for manufacturing of $L$ different products. So, $T C\left(T_{\mathrm{Z}}\right)$ is

$$
\begin{aligned}
& T C\left(T_{Z}\right)=\left[\pi_{0}\left(\sum_{i=1}^{L} Q_{i}\right)\right] C_{\pi 0}+K_{\pi 0}+C_{0} Q_{0}+K_{0}+\left[Q_{0} x_{0}\left(1-\theta_{1,0}\right)\right] C_{R, 0}+\left(Q_{0} x_{0} \varphi_{0}\right) C_{S, 0}+h_{4,0}\left(x_{0} \varphi_{0} Q_{0}\right) T_{Z} \\
& +h_{1,0}\left[\frac{H_{1,0} t_{1,0}}{2}+\frac{d_{1,0} t_{1,0}}{2}\left(t_{1,0}\right)+\frac{H_{2,0}+H_{1,0}}{2}\left(t_{2,0}\right)+\sum_{i=1}^{L}\left[\frac{Q_{i}}{2}\left(t_{1, i}\right)+H_{i}\left(t_{1, i}+t_{2, i}\right)\right]\right]+h_{2,0}\left(\frac{d_{1,0} t_{1,0}\left(1-\theta_{1,0}\right)}{2}\right)\left(t_{2,0}\right) \\
& +\sum_{i=1}^{L}\left\{\begin{array}{l}
Q_{i} C_{\mathrm{T}, i}+K_{\mathrm{T}, i}+\left[Q_{i} x_{i}\left(1-\theta_{1, i}\right)\right] C_{\mathrm{TR}, i}+\left(Q_{i} x_{i} \varphi_{i}\right) C_{S, i}+h_{4, i}\left(x_{i} \varphi_{i} Q_{i}\right) T_{Z}+h_{2, i}\left(\frac{d_{T 1, i} t_{1, i}\left(1-\theta_{1, i}\right)}{2}\right)\left(t_{2, i}\right) \\
+h_{1, i}\left[\frac{H_{1, i} t_{1, i}}{2}+\frac{d_{T 1, i} t_{1, i}}{2}\left(t_{1, i}\right)+\frac{H_{2, i}+H_{1, i}}{2}\left(t_{2, i}\right)+\frac{H_{2, i}}{2}\left(t_{3, i}\right)\right]
\end{array}\right\}
\end{aligned}
$$

By applying $E\left[x_{i}\right]$ (the expected values; for $\left.i=0,1,2, \ldots, L\right)$ to deal with random defective rates, replacing Eqs. (1) to (28) in $T C\left(T_{\mathrm{Z}}\right)$, and with extra derivation efforts, we obtain $E\left[T C U\left(T_{\mathrm{Z}}\right)\right]$ as follows (for details, please see Appendix B):

$$
\begin{aligned}
& E\left[T C U\left(T_{Z}\right)\right]=\left\{\begin{array}{l}
\frac{\left(1+\beta_{1,0}\right) K_{0}}{T_{Z}}+\left(1+\beta_{2,0}\right) C_{0} \pi_{0} \lambda_{0}+C_{0}\left(1-\pi_{0}\right) \lambda_{0} E_{00}+\frac{K_{0}}{T_{Z}}+C_{R, 0}\left(1-\theta_{1,0}\right)\left(1-\pi_{0}\right) \lambda_{0} E_{10} \\
+C_{S, 0}\left(1-\pi_{0}\right) \varphi_{0} \lambda_{0} E_{10}+\frac{h_{2,0} \lambda_{0}^{2}\left(1-\theta_{1,0}\right)^{2}\left(1-\pi_{0}\right)^{2}}{2 P_{2,0}}\left(E_{10}\right)^{2} T_{Z}+\frac{h_{1,0} \lambda_{0}^{2} T_{Z}}{2}\left(1-\pi_{0}\right)^{2}\left(E_{00}\right)^{2} E_{0 P} \\
+h_{4,0}\left(1-\pi_{0}\right) \varphi_{0} \lambda_{0} E_{10} T_{Z}+h_{1,0} \sum_{i=1}^{L}\left\{\frac{\lambda_{i}^{2} T_{Z}\left(E_{0 i}\right)^{2}}{2\left[\left(1+\alpha_{1, i}\right) P_{1, i}\right]}+\left(\sum_{i=1}^{L}\left[\lambda_{i} T_{Z} E_{0 i}\right]-\sum_{j=1}^{i}\left[\lambda_{j} T_{Z} E_{0 j}\right]\right) \lambda_{i} E_{0 i} E_{2 i}\right\}
\end{array}\right\} \\
&+\sum_{i=1}^{L}\left\{\begin{array}{l}
{\left[\left(1+\alpha_{3, i}\right) C_{i}\right] \lambda_{i} E_{0 i}+\frac{\left[\left(1+\alpha_{2, i}\right) K_{i}\right]}{T_{Z}}+\left[\left(1+\alpha_{3, i}\right) C_{R, i}\right]\left(1-\theta_{1, i}\right) \lambda_{i} E_{1 i}} \\
+C_{S, i} \varphi_{i} \lambda_{i} E_{1 i}+h_{4, i} \varphi_{i} \lambda_{i} E_{1 i} T_{Z}+h_{2, i} \frac{T_{Z}\left(1-\theta_{1, i}\right)^{2}}{2\left[\left(1+\alpha_{1, i}\right) P_{2, i}\right]}\left(\lambda_{i} E_{1 i}\right)^{2}+h_{1, i}\left[\frac{T_{Z}}{2}\right]\left(\lambda_{i} E_{0 i}\right)^{2} E_{3 i}
\end{array}\right\}
\end{aligned}
$$

Apply the $1^{\text {st }}$ and $2^{\text {nd }}$ derivatives to $E\left[T C U\left(T_{\mathrm{Z}}\right)\right]$, the following can be gained:

$$
\begin{aligned}
& \frac{d E\left[T C U\left(T_{Z}\right)\right]}{d\left(T_{Z}\right)}=\left\{\begin{array}{l}
-\frac{\left(1+\beta_{1,0}\right) K_{0}}{T_{Z}^{2}}-\frac{K_{0}}{T_{Z}^{2}}+h_{2,0}\left[\frac{\left(1-\theta_{1,0}\right)^{2}\left(1-\pi_{0}\right)^{2} \lambda_{0}{ }^{2}}{2\left(P_{2,0}\right)}\right]\left(E_{10}\right)^{2}+h_{1,0} \frac{\lambda_{0}^{2}\left(1-\pi_{0}\right)^{2}}{2}\left(E_{00}\right)^{2} E_{0 P} \\
+h_{4,0}\left[\left(1-\pi_{0}\right) \lambda_{0} \varphi_{0}\left(E_{10}\right)\right]+h_{1,0} \sum_{i=1}^{L}\left\{\frac{\lambda_{i}^{2}\left(E_{0 i}\right)^{2}}{2\left[\left(1+\alpha_{1, i}\right) P_{1, i}\right]}+\left(\sum_{i=1}^{L}\left[\lambda_{i} E_{0 i}\right]-\sum_{j=1}^{i}\left[\lambda_{j} E_{0 j}\right]\right) \lambda_{i} E_{0 i} E_{2 i}\right\}
\end{array}\right\} \\
& +\sum_{i=1}^{L}\left\{-\frac{\left(1+\alpha_{2, i}\right) K_{i}}{T_{Z}^{2}}+h_{4, i} \varphi_{i} \lambda_{i} E_{1 i}+h_{2, i}\left[\frac{\lambda_{i}^{2}\left(1-\theta_{1, i}\right)^{2}}{2\left(1+\alpha_{1, i}\right) P_{2, i}}\right]\left(E_{1 i}\right)^{2}+h_{1, i} \frac{\left(\lambda_{i} E_{0 i}\right)^{2}}{2} E_{3 i}\right\} \\
& \frac{d^{2} E\left[T C U\left(T_{Z}\right)\right]}{d\left(T_{Z}\right)^{2}}=\frac{2\left[\left(1+\beta_{1,0}\right) K_{0}\right]}{T_{Z}{ }^{3}}+\frac{2 K_{0}}{T_{Z}{ }^{3}}+\sum_{i=1}^{L}\left\{\frac{2\left[\left(1+\alpha_{2, i}\right) K_{i}\right]}{T_{Z}{ }^{3}}\right\}>0
\end{aligned}
$$

In Eq. (32), because $\beta_{1,0}$, setup costs $K_{0}$ and $K_{i}, \alpha_{2, i}$, and $T_{\mathrm{Z}}$ are all positive; thus, $E\left[T C U\left(T_{\mathrm{Z}}\right)\right]$ is convex. Then, setting the first derivative result Eq. (31) $=0$, we gain the optimal $T_{Z}{ }^{*}$. 


$$
T_{Z}^{*}=\sqrt{\frac{2\left\{\left(2+\beta_{1,0}\right) K_{0}+\sum_{i=1}^{L}\left[\left(1+\alpha_{2, i}\right) K_{i}\right]\right\}}{h_{2,0}\left[\frac{\left(1-\theta_{1,0}\right)^{2}\left(1-\pi_{0}\right)^{2} \lambda_{0}^{2}}{\left(P_{2,0}\right)}\right]\left(E_{10}\right)^{2}+2 h_{4,0}\left(1-\pi_{0}\right) \lambda_{0} \varphi_{0}\left(E_{10}\right)+h_{1,0} \lambda_{0}^{2}\left(1-\pi_{0}\right)^{2}\left(E_{00}\right)^{2} E_{0 P}}}
$$

Please refer to Eqs. (B-2) and (B-3) (in Appendix B) for the details for $E_{00}, E_{10}, E_{0 j}, E_{0 P}, E_{0 i}, E_{1 i}, E_{2 i}$, and $E_{3 i}$.

\subsection{Discussion on the setup times condition}

If the summation of the setup times $S_{\mathrm{i}}$ is greater than the idle time in a cycle length (see Fig. 1), then, it is required to calculate $T_{\min }$ (as pointed out in Nahmias (2009)) and select the maximum of $\left(T_{Z^{*}}, T_{\min }\right)$ as the final answer for cycle length for the proposed problem.

$$
T_{\min }=\frac{\sum_{i=0}^{L}\left(S_{i}\right)}{1-\left\{\frac{\lambda_{0}\left(1-\pi_{0}\right)}{\left[1-\varphi_{0} E\left[x_{0}\right]\right]}\left(\frac{1}{P_{1,0}}+\frac{E\left[x_{0}\right]\left(1-\theta_{1,0}\right)}{P_{2,0}}\right)+\sum_{i=1}^{L} \frac{\lambda_{i}}{\left[1-\varphi_{i} E\left[x_{i}\right]\right]}\left[\frac{1}{P_{T 1, i}}+\frac{E\left[x_{i}\right]\left(1-\theta_{1, i}\right)}{P_{T 2, i}}\right]\right\}}
$$

\subsection{Prerequisite condition of the proposed problem}

The following prerequisite formulas must hold to ensure the equipment has sufficient capacity in both stages of this study for manufacturing and reworking common parts and $L$ different products (Nahmias, 2009).

$$
\begin{aligned}
& {\left[\left(t_{1,0}+t_{2,0}\right)+\sum_{i=1}^{L}\left(t_{1, i}+t_{2, i}\right)\right]<T_{Z} \text { or }\left[Q_{0}\left(\frac{1}{P_{1,0}}+\frac{E\left[x_{0}\right]\left(1-\theta_{1,0}\right)}{P_{2,0}}\right)+\sum_{i=1}^{L} Q_{i}\left(\frac{1}{P_{T 1, i}}+\frac{E\left[x_{i}\right]\left(1-\theta_{1, i}\right)}{P_{T 2, i}}\right)\right]<T_{Z}} \\
& \text { or }\left\{\left(\frac{\lambda_{0}\left(1-\pi_{0}\right)}{\left[1-\varphi_{0} E\left[x_{0}\right]\right]}\right)\left(\frac{1}{P_{1,0}}+\frac{E\left[x_{0}\right]\left(1-\theta_{1,0}\right)}{P_{2,0}}\right)+\sum_{i=1}^{L}\left(\frac{\lambda_{i}}{\left[1-\varphi_{i} E\left[x_{i}\right]\right]}\right)\left[\frac{1}{P_{T 1, i}}+\frac{E\left[x_{i}\right]\left(1-\theta_{1, i}\right)}{P_{T 2, i}}\right]\right\}<1
\end{aligned}
$$

\section{Example}

A multiproduct batch plan needs to meet the annual requirements of five different products. This plan employs a two-stage postponement strategy to cope with the common part among these products. It also adopts an outsourcing alternative for common parts in stage-1, an overtime option for end products in stage-2, and quality reassurance in both stages. Table 1 shows the assumption of variables' values in stage one, while Tables 2 and 3 exhibit the relating variables' values in stage two. In contrast, the variables' values used for a single-stage fabrication plan for the same problem are displayed in Appendix C (see Tables C-1 and C-2).

Table 1

Assumption of variables' values in stage 1

\begin{tabular}{cccccccccc}
\hline$\gamma$ & $\lambda_{0}$ & $P_{1,0}$ & $x_{0}$ & $C_{\mathrm{S}, 0}$ & $h_{1,0}$ & $\theta_{1,0}$ & $\delta$ & $\beta_{1,0}$ & $\varphi_{0}$ \\
0.5 & 17406 & 120000 & $2.5 \%$ & $\$ 10$ & $\$ 8$ & 0.046 & 0.5 & -0.7 & 0.09 \\
\hline$C_{0}$ & $K_{0}$ & $P_{2,0}$ & $C_{\mathrm{R}, 0}$ & $\pi_{0}$ & $\mathrm{i}_{0}$ & $\theta_{2,0}$ & $h_{2,0}$ & $\beta_{2,0}$ & $h_{4,0}$ \\
$\$ 40$ & $\$ 8500$ & 96000 & $\$ 25$ & 0.4 & 0.2 & 0.046 & $\$ 8$ & 0.4 & $\$ 8$ \\
\hline
\end{tabular}

Table 2

Assumption of variables' values in stage 2 ( 1 of 2 )

\begin{tabular}{cccccccccc}
\hline Product $i$ & $\alpha_{1, i}$ & $P_{1, i}$ & $\alpha_{2, i}$ & $K_{i}$ & $\alpha_{3, i}$ & $C_{i}$ & $i_{i}$ & $h_{1, i}$ & $\lambda_{i}$ \\
\hline 1 & 0.5 & 112258 & 0.1 & $\$ 8500$ & 0.25 & $\$ 40$ & 0.2 & $\$ 16$ & 3000 \\
2 & 0.5 & 116066 & 0.1 & $\$ 9000$ & 0.25 & $\$ 50$ & 0.2 & $\$ 18$ & 3200 \\
3 & 0.5 & 120000 & 0.1 & $\$ 9500$ & 0.25 & $\$ 60$ & 0.2 & $\$ 20$ & 3400 \\
4 & 0.5 & 124068 & 0.1 & $\$ 10000$ & 0.25 & $\$ 70$ & 0.2 & $\$ 22$ & 3600 \\
5 & 0.5 & 128276 & 0.1 & $\$ 10500$ & 0.25 & $\$ 80$ & 0.2 & $\$ 24$ & 3800 \\
\hline
\end{tabular}


Table 3

Assumption of variables' values in stage 2 (2 of 2)

\begin{tabular}{cccccccccc}
\hline Product $i$ & $x_{i}$ & $\theta_{1, i}$ & $P_{2, i}$ & $C_{\mathrm{S}, i}$ & $h_{2, i}$ & $h_{4, i}$ & $\theta_{2, i}$ & $C_{\mathrm{R}, i}$ & $\varphi_{i}$ \\
\hline 1 & $2.5 \%$ & 0.046 & 89806 & $\$ 10$ & $\$ 16$ & $\$ 16$ & 0.046 & $\$ 25$ & 0.09 \\
2 & $7.5 \%$ & 0.094 & 92852 & $\$ 15$ & $\$ 18$ & $\$ 18$ & 0.094 & $\$ 30$ & 0.18 \\
3 & $12.5 \%$ & 0.146 & 96000 & $\$ 20$ & $\$ 20$ & $\$ 20$ & 0.146 & $\$ 35$ & 0.27 \\
4 & $17.5 \%$ & 0.200 & 99254 & $\$ 25$ & $\$ 22$ & $\$ 22$ & 0.200 & $\$ 40$ & 0.36 \\
5 & $22.5 \%$ & 0.258 & 102621 & $\$ 30$ & $\$ 24$ & $\$ 24$ & 0.258 & $\$ 45$ & 0.45 \\
\hline
\end{tabular}

Through computing Eqs. (33) and (29), we find $T_{\mathrm{Z}}^{*}=0.5791$ and $E\left[T C U\left(T_{\mathrm{Z}}{ }^{*}\right)\right]=\$ 2,422,005$ for our proposed delayed differentiation multiproduct model. Figure 5 clearly illustrates the convexity of $E\left[T C U\left(T_{\mathrm{Z}}\right)\right]$ concerning $T_{\mathrm{Z}}$. It exposes that $E\left[T C U\left(T_{\mathrm{Z}}\right)\right]$ upsurges both directions as $T_{\mathrm{Z}}$ deviates from $T_{\mathrm{Z}} *$.

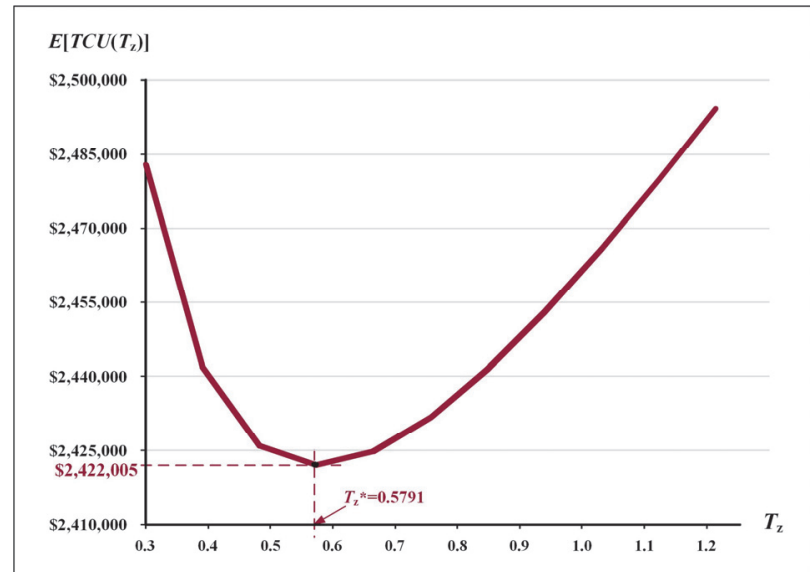

Fig. 5. Behavior of $E\left[T C U\left(T_{\mathrm{Z}}\right)\right]$ concerning $T_{\mathrm{Z}}$

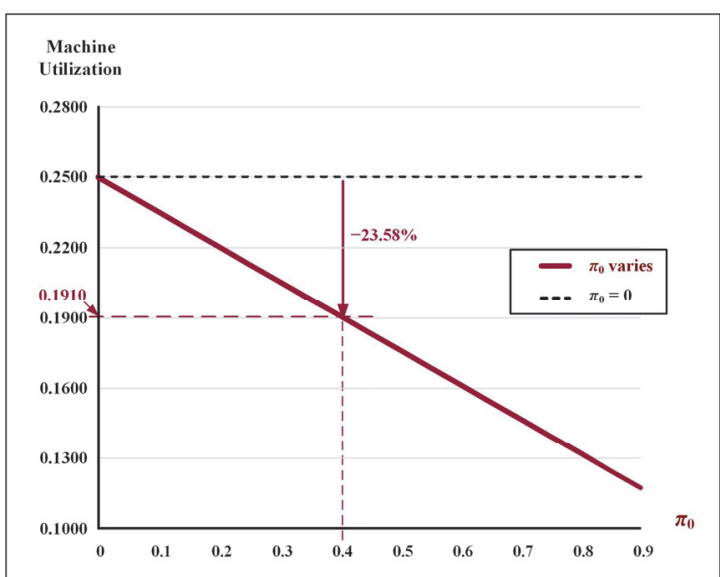

Fig. 6. The impact of outsourcing in stage one on the machine utilization

\subsection{The impact of the outsourcing and overtime strategies on the proposed problem}

The present study implements two different strategies to reduce the uptimes in both fabrication stages. Their effects are analyzed explicitly in terms of machine utilization and the cost they are paying as follows. Figure 6 depicts the impact of outsourcing (in stage one) on machine utilization. It reveals that when outsider suppliers provide $40 \%$ of the common parts, the utilization drops $23.58 \%$ (i.e., from 0.2500 to 0.1910 , please refer to Table D-1 in Appendix D for details).

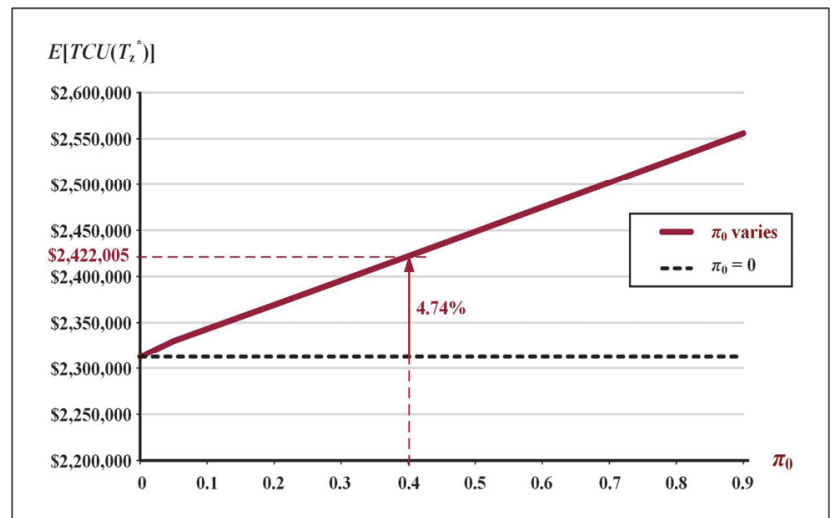

Fig. 7. Changes in $E\left[T C U\left(T_{\mathrm{Z}}^{*}\right)\right]$ concerning outsourcing percentage

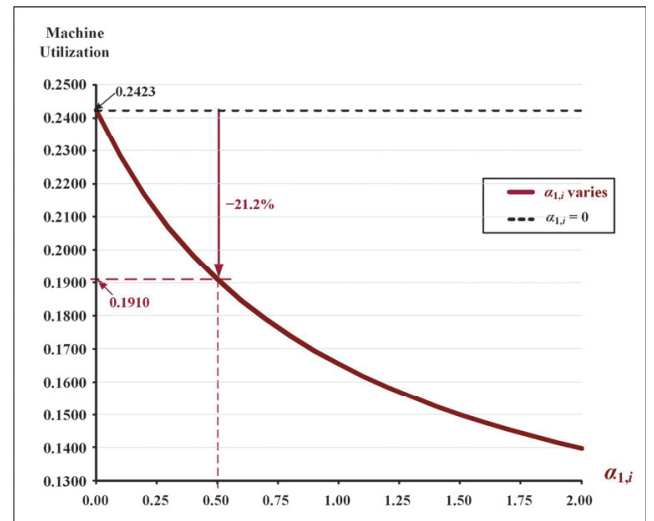

Fig. 8. The influence of overtime (in stage two) on the machine utilization

Fig. 7 illustrates that to reduce machine utilization by $23.58 \%$, we are paying the price of $4.74 \%$ in system cost $E\left[T C U\left(T_{Z}^{*}\right)\right]$ increase, i.e., the system cost goes up from $\$ 2,312,415$ to $\$ 2,422,005$ (see Table D-1 in Appendix D). Fig. 8 exhibits the influence of overtime (in stage two) on machine utilization. It reveals that when output rate increases $50 \%$ in the fabrication of end products, the utilization declines $21.2 \%$ (i.e., from 0.2423 to 0.1910 , please refer to Table D-2 in Appendix D for details).

Fig. 9 shows that for reducing machine utilization by $21.2 \%$, we are paying the price of $13.26 \%$ in system cost $E\left[T C U\left(T_{\mathrm{Z}}{ }^{*}\right)\right]$ increase, i.e., the system cost goes up from $\$ 2,138,414$ to $\$ 2,422,005$ (see Table D-2 in Appendix D). 


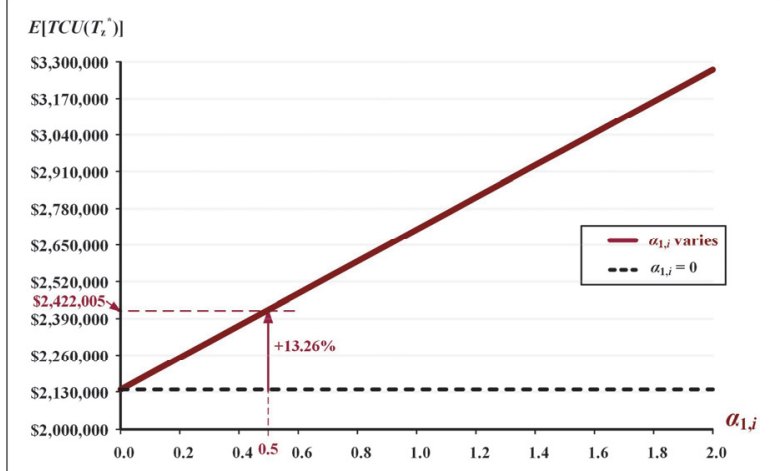

Fig. 9 Changes in $E\left[T C U\left(T_{Z}^{*}\right)\right]$ concerning overtime factor

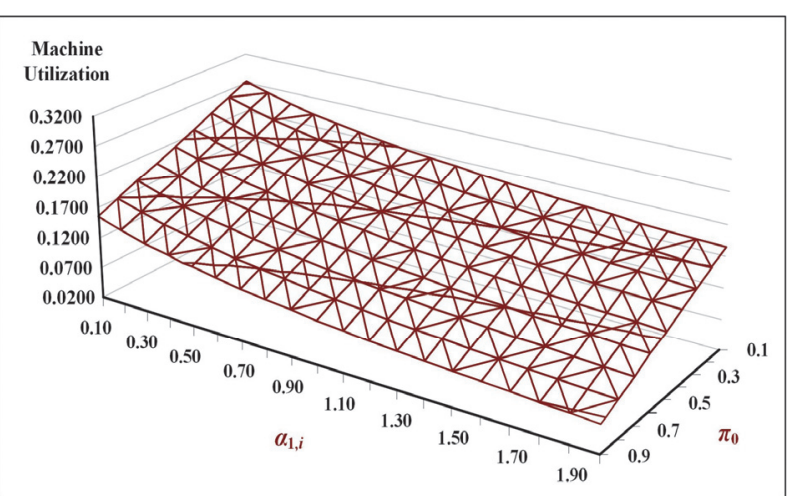

Fig. 10. The collective impact of $\alpha_{1, i}$ and $\pi_{0}$ on utilization

\subsection{The collective influence of the outsourcing and overtime strategies on the proposed problem}

The collective impact of overtime factor $\alpha_{1, i}$ and outsourcing ratio $\pi_{0}$ on machine utilization are explored and depicted in Fig. 10. It indicates that as $\alpha_{1, i}$ rises, the machine utilization decreases noticeably; as $\pi_{0}$ goes up, utilization drops severely. Fig. 11 illustrates the analytical outcomes of the combined effect of overtime factor $\alpha_{1, i}$ and outsourcing ratio $\pi_{0}$ on system cost $E\left[T C U\left(T_{\mathrm{Z}}{ }^{*}\right)\right]$. It clearly illustrates that as both $\alpha_{1, i}$ and $\pi_{0}$ rise, the system cost increases noticeably. Our example shows that $\alpha_{1, i}$ has more impact than $\pi_{0}$ on the system $\operatorname{cost} E\left[T C U\left(T_{\mathrm{Z}}^{*}\right)\right]$ increase. Fig. 12 explicitly analyzes the individual and collective impact of $\alpha_{1, i}$ and $\pi_{0}$ on system cost. Based on our parameter assumptions, this study suggests that it is more economical first to outsource $40 \%$ of the common parts and, in the meantime, gradually implement the overtime factor. As soon as we reach the point of $\alpha_{1, i}=0.5$ and $\pi_{0}=0.4$, to further reduce the machine utilization, it is more economical to stop increase the overtime factor (i.e., let $\alpha_{1, i}$ remains at 0.5 ) and solely increase outsourcing percentage. Our proposed model can conduct a similar analysis for any given parameter assumptions and offers in-depth analytical information to facilitate managerial decisionmaking.

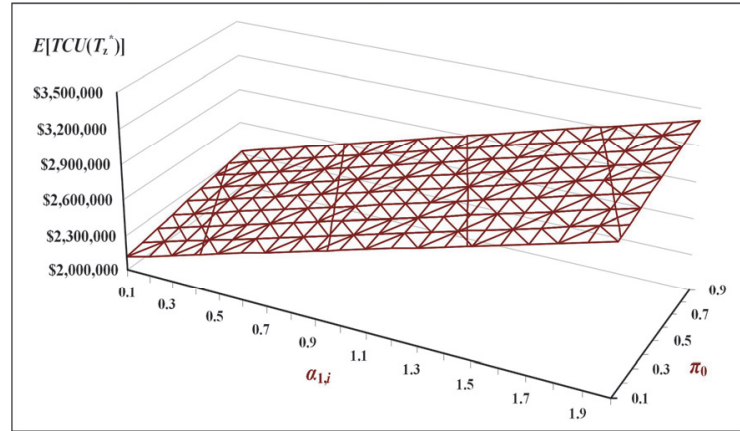

Fig. 11. The combined effect of $\alpha_{1, i}$ and $\pi_{0}$ on $E\left[T C U\left(T_{Z}^{*}\right)\right]$

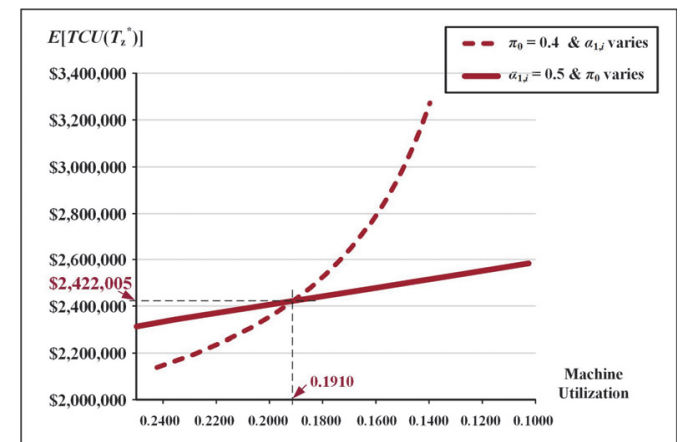

Fig. 12. The individual and collective impact of $\alpha_{1, i}$ and $\pi_{0}$ on the system cost

\subsection{Impact of common part's completion rate and its value on the proposed problem}

The analytical outcomes of the influence of common part's completion rate and its value on the proposed problem are illustrated below.

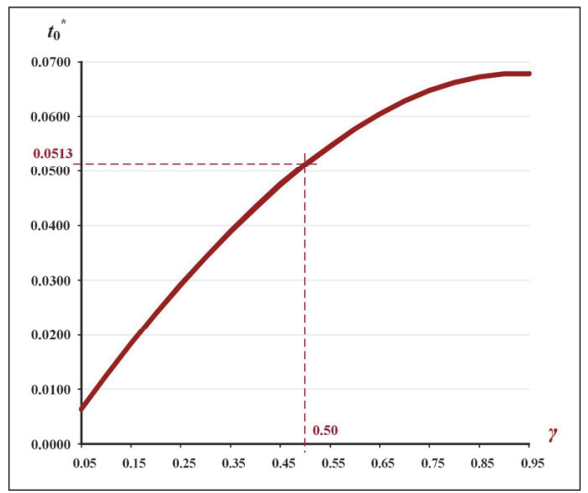

Fig. 13. The common part's optimal uptime and rework time $t_{0}{ }^{*}$ concerning $\gamma$

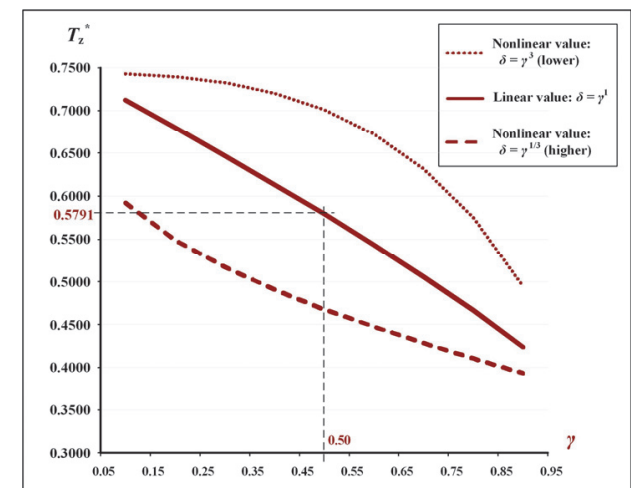

Fig. 14. The impact of the linear/nonlinear relationships between $\delta$ and $\gamma$ on $T_{\mathrm{Z}}$ * 
Fig. 13 displays the influence of $\gamma$ on the optimal fabrication uptime plus rework time $t_{0}{ }^{*}$. It reveals that as $\gamma$ rises, more fabrication and rework time for the common part are needed. At our assumption where $\gamma=0.5, t_{0}{ }^{*}=0.0513$ (see Table D-1 in Appendix D). It also indicates that at $\gamma=0.5$, by outsourcing $40 \%$ of common parts, $t_{0}{ }^{*}$ drops $37.5 \%$ (i.e., it declines from 0.0821 to 0.0513 ). The impact of the linear (i.e., $\delta=\gamma^{1}$ ) and nonlinear (e.g., $\delta=\gamma^{1 / 3}$ or $\delta=\gamma^{3}$ ) relationships between $\delta$ and $\gamma$ on the optimal decision variable $T_{\mathrm{Z}}{ }^{*}$ is explicitly explored and exhibited in Fig. 14. First, it reconfirms our example that when $\gamma$ $=0.50, T_{\mathrm{Z}} *=0.5791$. It also reveals the crucial information of $T_{\mathrm{Z}} *$ variations concerning nonlinear relationships between $\delta$ and $\gamma$.

\subsection{The influence of quality reassurances on the proposed problem}

The collective impact of average defective and scrap rates on $E\left[T C U\left(T_{\mathrm{Z}}^{*}\right)\right]$ is illustrated in Fig. 15. It indicates that as $\bar{\varphi}$ rises, $E\left[T C U\left(T_{\mathrm{Z}}^{*}\right)\right]$ surges noticeable; as $\bar{x}$ increases, the system cost upsurges significantly.

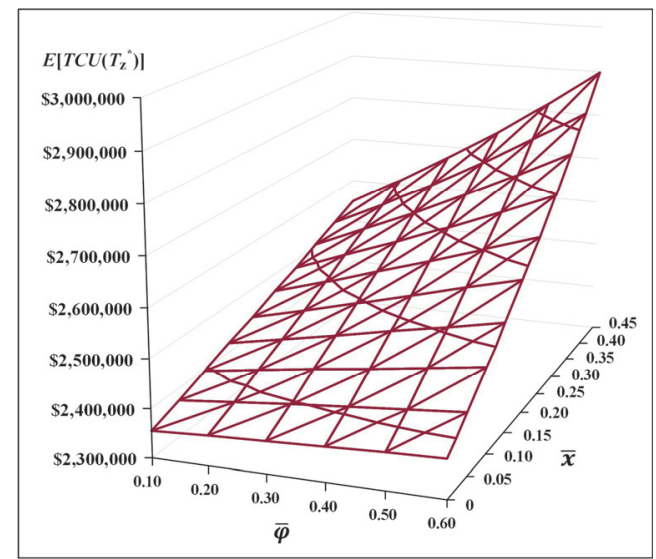

Fig. 15. The variations of $E\left[T C U\left(T_{\mathrm{Z}}^{*}\right)\right]$ concerning the collective impact from $\bar{x}$ and $\bar{\varphi}$

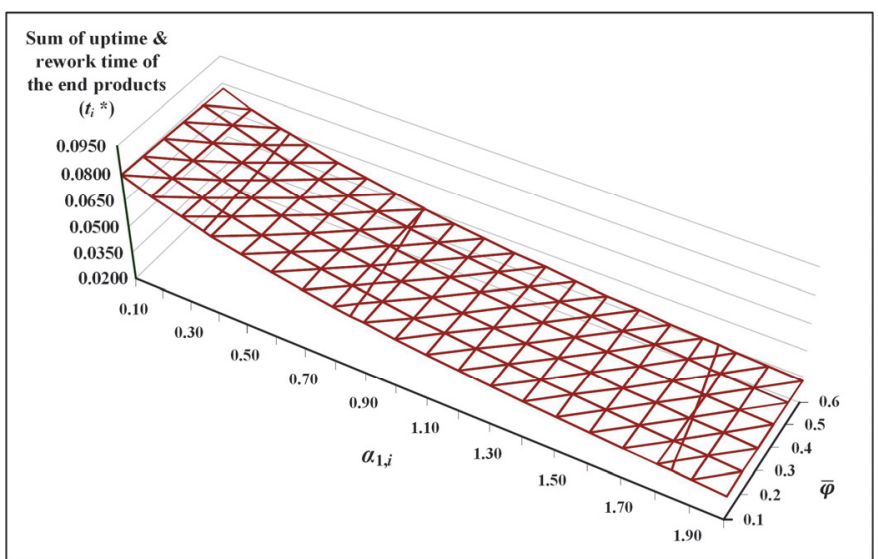

Fig. 16. The variations of $t_{i}{ }^{*}$ concerning the collective impact of $\alpha_{1, i}$ and $\bar{\varphi}$

The combined influence of overtime factor $\alpha_{1, i}$ and average scrap rate on the sum of end products' uptime and rework time is depicted in Figure 16. It shows that as $\bar{\varphi}$ rises, $t_{i}^{*}$ changes slightly; as the overtime factor $\alpha_{1, i}$ increases, $t_{i}^{*}$ declines severely. Fig. 17 exhibits the analytical outcomes of cost contributors to $E\left[T C U\left(T_{\mathrm{Z}}{ }^{*}\right)\right]$. It shows that total quality costs add up to $3.58 \%$ (i.e., $0.15 \%$ in stage one and $3.43 \%$ in stage two; please refer to Tables D-1 and D-2). The outsourcing and overtime relevant costs contribute $16.28 \%$ and $11.75 \%$ of $E\left[T C U\left(T_{\mathrm{Z}}{ }^{*}\right)\right]$, respectively. The in-house variable cost for common parts and end products contribute $17.51 \%$ and $46.89 \%$, respectively.

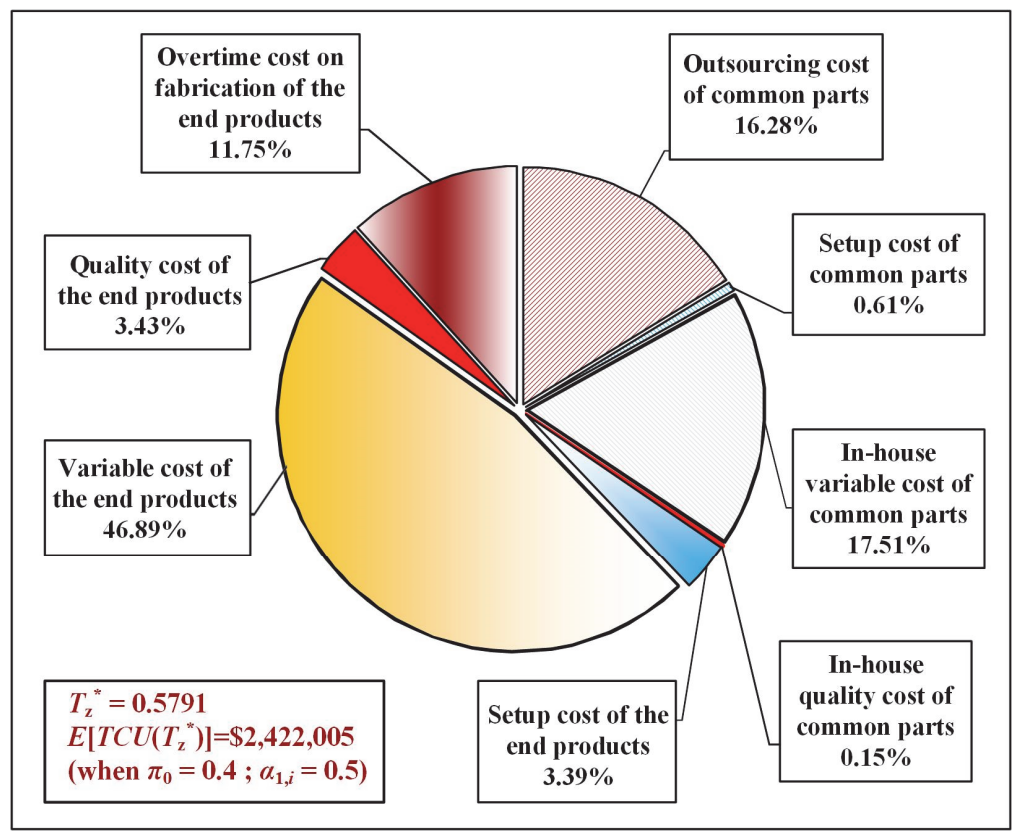

Fig. 17. The breakup of $E\left[T C U\left(T_{\mathrm{Z}}^{*}\right)\right]$ 


\subsection{Discussion and comparisons}

In addition to exposing the system characteristics mentioned earlier, the proposed model can analyze various previously inaccessible managerial information on the problem. For example, Fig. 18 illustrates the variations of $\left(t_{1, i}+t_{2, i}\right)$ of each end product concerning $\alpha_{1, i}$. It reveals that as overtime factor $\alpha_{1, i}$ increases, the sum of each end product's uptime and reworking time declines considerably.

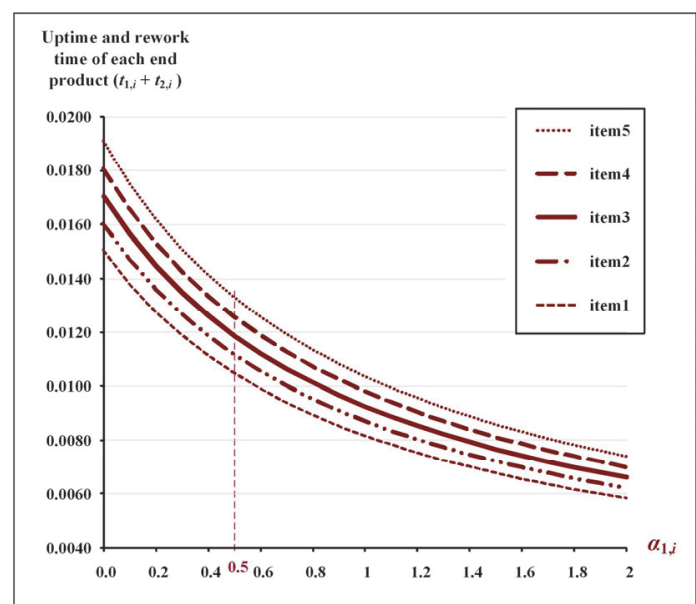

Fig. 18. The sum of each end product's uptime and rework time $\left(t_{1, i}+t_{2, i}\right)$ concerning $\alpha_{1, i}$

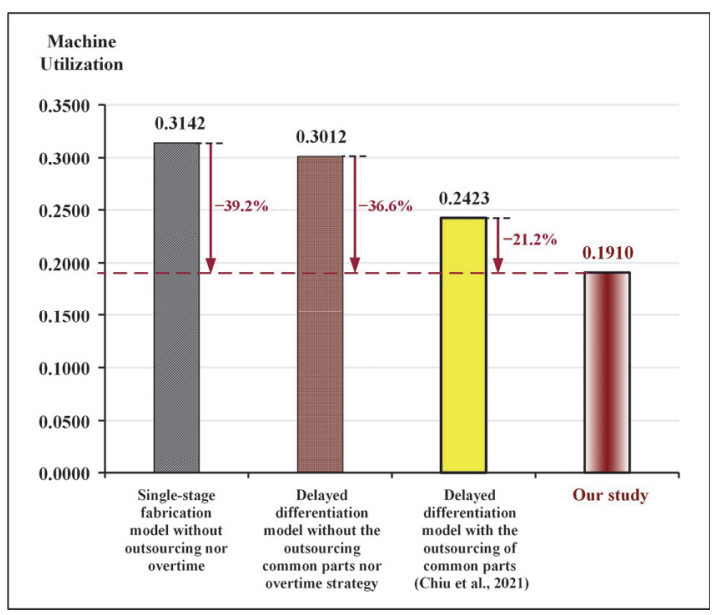

Fig. 19. The comparison of our machine utilization with that in other similar models

Fig. 19 compares the proposed model's machine utilization with that in other similar models. It demonstrates that by implementing the dual strategies (i.e., outsourcing and overtime options) on reducing fabrication times, our proposed model has the lowest machine utilization (i.e., 0.1910 ), which is a $21.2 \%$ lower than a model solely using outsourcing in stage one (Chiu et al., 2021). It is a $36.6 \%$ and $39.2 \%$ less utilization than the model without applying any expediting strategy or without delayed differentiation (i.e., the single-stage manufacturing scheme). Further analysis discloses that we are paying the price of a $13.26 \%, 19.40 \%$, or $14.00 \%$ increase in $E\left[T C U\left(T_{\mathrm{Z}}{ }^{*}\right)\right]$, respectively, for the utilization reduction exhibited in Fig. 19. This crucial information was previously inaccessible to managers in supporting their production planning and management.

\section{Conclusions}

To simultaneously face the time and quality demands of various goods externally and meet limited capacity internally, production planners today must seek an efficient tool to make cost-effective fabrication decisions. Motivated by helping their decision-making, this study presents a two-stage delayed-differentiation multiproduct model that considers the outsourcing options for common parts, overtime strategy for end products, and quality reassurance. The researchers use the mathematical modeling, analysis, and optimization approach to decide the best rotation cycle length that minimizes the system's expenses. We use a numerical illustration to validate our result's applicability and exhibit the proposed model's capability.

The present work contributes to practical multiproduct-fabrication by

(1) Deriving the optimal manufacturing policy for a delayed-differentiation multiproduct system with dual uptime reduction policies and quality reassurance (refer to Sections 2 and 3, and Figure 5);

(2) Offering a decisional model that allows present-day production planners to explore the collective/separate effect of a quality-ensured and dual uptime reduction strategy on (i) the problem's operating policy (see Figures 6, 8, 10, 12, and 13) and (ii) crucial system performance indicators (refer to Figures 7, 9, 11, and 14 to 18) to help cost-effective decision- making; and

(3) Comparing/demonstrating the model's performance with various closely related models (see Figure 19).

Combining a discontinuous product-shipment plan into this problem's context will be a worthy study subject in the future.

\section{Acknowledgments}

The authors thank the Ministry of Science and Technology of Taiwan for its sponsorship of this research (Grant No.: MOST 109-2221-E-324-015). 


\section{References}

Akkermans, H., Van Oppen, W., Wynstra, F., \& Voss, C. (2019). Contracting outsourced services with collaborative key performance indicators. Journal of Operations Management, 65(1), 22-47.

Aouam, T., \& Kumar, K. (2019). On the effect of overtime and subcontracting on supply chain safety stocks. Omega, 89, 120.

Arun, P., Lincon, S.A., \& Prabhakaran, N. (2019). An automated method for the analysis of bearing vibration based on spectrogram pattern matching. Journal of Applied Research and Technology, 17(2), 126-136.

Blecker, T., \& Abdelkafi, N. (2006). Complexity and variety in mass customization systems: Analysis and recommendations. Management Decision, 44(7), 908-929.

Cerdá, J., Cafaro, V.G., Cafaro, D.C. (2020). Synchronizing Operations in Multiproduct Batch Facilities Producing Semifinished and Final Products. Industrial and Engineering Chemistry Research, 59 (29), 13113-13131.

Chakraborty, D., Jana, D.K., \& Roy, T.K. (2020). Multi-warehouse partial backlogging inventory system with inflation for non-instantaneous deteriorating multi-item under imprecise environment. Soft Computing, 24(19), 14471-14490.

Chiu, Y-S.P., Chen, H-C., Chang, H-H., \& Hwang, M-H. (2019a). Determining rotation cycle and distribution frequency for a vendor-buyer integrated multi-item system considering an external provider and rework. International Journal of Industrial Engineering Computations, 10(4), 505-520.

Chiu, Y-S.P., Chiu, V., Lin, H-D., \& Chang, H-H. (2019b). Meeting multiproduct demand with a hybrid inventory replenishment system featuring quality reassurance. Operations Research Perspectives, 6, Art. No. 100112, 1-8.

Chiu, Y-S.P., Chiu, V., Wang, Y., \& Hwang, M-H. (2020a). A postponement model for multi-item replenishment decision considering overtime, commonality, and quality reassurance. International Journal of Industrial Engineering Computations, 11(4), 509-524.

Chiu, Y.-S.P., Zhao, Z.-Y., Chiu, S.W., \& Chiu, V. (2020b). A vendor-buyer coordinated system featuring an unreliable machine, scrap, outsourcing, and multiple shipments. International Journal of Industrial Engineering Computations, 11(3), 341-358.

Chiu, Y-S.P., Sung, P-C., \& Chiu, V. (2020c) A two-phase solution approach for a manufacturing- distribution problem with rework, outsourcing, and multi-shipment policy. Journal of Applied Engineering Science, 18(4), 505-509.

Chiu, Y-S.P., Chang, H-H., Chiu, T., \& Chiu, S.W. (2021). A multi-item batch fabrication problem featuring delayed product differentiation, outsourcing, and quality assurance. International Journal of Industrial Engineering Computations, 12(1), 64-78.

Dellaer, N.P., \& Melo, M.T. (1998). Make-to-order policies for a stochastic lot-sizing problem using overtime. International Journal of Production Economics, 56-57, 79-97.

Hamers, H., Klijn, F., \& Slikker, M. (2019). Implementation of optimal schedules in outsourcing with identical suppliers. Mathematical Methods of Operations Research, 89(2), 173-187.

Jabbarzadeh, A., Haughton, M., \& Pourmehdi, F. (2019). A robust optimization model for efficient and green supply chain planning with postponement strategy. International Journal of Production Economics, 214, 266-283.

Jaramillo, F., \& Erkoc, M. (2017). Minimizing total weighted tardiness and overtime costs for single machine preemptive scheduling. Computers and Industrial Engineering, 107, 109-119.

Jha, K.K., Thakkar, J.J., \&Thanki, S.J. (2020). Cycle time reduction in outsourcing process: case of an Indian aerospace industry. International Journal of Advanced Manufacturing Technology, 106(9-10), 4355-4373.

Jimmy, J., Roesyadi, A., Suprapto, S., Kurniawansyah, F., Anggraini, W., \& Rahmawati, R. (2020). Activated carbon from bamboo waste: Effect of activation sequences and iron-cobalt impregnation to material properties and catalyst performance. Journal of Applied Engineering Science, 18(1), 1-9.

Jirjahn, U. (2008). On the determinants of shift work and overtime work: Evidence from German establishment data. British Journal of Industrial Relations, 46(1), 133-168.

Kamien, M.I., Li, L., \& Samet, D. (1989). Bertrand competition with subcontracting. RAND Journal of Economics, 20, 553567.

Kenyon, G.N., Meixell, M.J., \& Westfall, P.H. (2016). Production outsourcing and operational performance: An empirical study using secondary data. International Journal of Production Economics, 171(3), 336-349.

Kikuchi, H., Odagiri, Y., Ohya, Y., Nakanishi, Y., Shimomitsu, T., Theorell, T., \& Inoue, S. (2020). Association of overtime work hours with various stress responses in 59,021 Japanese workers: Retrospective cross-sectional study. PLoS ONE, 15(3), Art. No. e0229506.

Kim, J.-S., Shin, K.-C., \& Park, S.-K. (2000). An optimal algorithm for repairable-item inventory system with depot spares. Journal of the Operational Research Society, 51(3), 350-357.

Larkin, E.V., \& Privalov, A.N. (2019). Engineering method of fault -tolerant system simulations. Journal of Applied Engineering Science, 17(3), 295-303.

Lin, H-D., Chen, Y-R., Chiu, V., \& Chiu, Y-S.P. (2019). A decision model for a quality-assured EPQ-based intra-supply chain system considering overtime option. Journal of Applied Engineering Science 17(3), 362-371.

Mabude, K., Malela-Majika, J.-C., \& Shongwe, S.C. (2020). A new distribution-free generally weighted moving average monitoring scheme for detecting unknown shifts in the process location. International Journal of Industrial Engineering Computations, 11(2), 235-254.

Mojeed, H.A., Bajeh, A.O., Balogun, A.O., \& Adeleke, H.O. (2019). Memetic approach for multi-objective overtime planning 
in software engineering projects. Journal of Engineering Science and Technology, 14(6), 3213-3233.

Nahmias, S. (2009). Production \& Operations Analysis. McGraw-Hill Inc. New York.

Nachiappan, S.P., Jawahar, N., \& Kumar, N.K. (2008). Operating parameters for a single-vendor multiple-buyers Vendor Managed Inventory System with Outsourcing. International Journal of Operational Research, 3(3), 336-361.

Ouaddi, K., Mhada, F.-Z., \& Benadada, Y. (2020). Memetic algorithm for multi-tours dynamic vehicle routing problem with overtime (Mdvrpot). International Journal of Industrial Engineering Computations, 11(4), 643-662.

Roy, A., Maity, K., Kar, S., \& Maiti, M. (2009). A production-inventory model with remanufacturing for defective and usable items in fuzzy-environment. Computers \& Industrial Engineering, 56(1), 87-96.

Seth, D., \& Panigrahi, A. (2015). Application and evaluation of packaging postponement strategy to boost supply chain responsiveness: A case study. Production Planning and Control, 26, 1069-1089.

Sonntag, D., \& Kiesmüller, G.P. (2018). Disposal versus rework - Inventory control in a production system with random yield. European Journal of Operational Research, 267(1), 138-149.

Uniyal, N., Pant, S., \& Kumar, A. (2020). An overview of few nature inspired optimization techniques and its reliability applications. International Journal of Mathematical, Engineering and Management Sciences, 5(4), 732-743.

Van Hoek, R.I. (1999). Postponement and the reconfiguration challenge for food supply chains. Supply Chain Management, 4(1), 18-34.

Van Mieghem, J.A. (1999). Coordinating investment, production and subcontracting. Management Science, 45, 954-971.

\section{Appendix - A}

$T_{\mathrm{Z}} \quad=$ the replenishing cycle length (i.e., decision variable),

$\lambda_{i} \quad=$ annual demand rate for $L$ distinct end product $i$ (where $i=1,2, \ldots, L$ ),

$\lambda_{0}=$ annual demand rate of the common part,

$Q_{i} \quad=$ lot size for product $i$,

$Q_{0} \quad=$ in-house lot size for common parts in stage 1 ,

$I(t)_{i} \quad=$ stock level at time $t$ (where $\left.i=0,1,2, \ldots, L\right)$,

$H_{3,0}=$ stock level of common parts upon receipt of the outsourced items,

$H_{2,0}=$ common parts' stock level when rework process completes,

$H_{1,0}=$ common parts' stock level when fabrication process finishes,

$t_{1,0}=$ common parts' fabrication uptime,

$t_{2,0}=$ common parts' rework time,

$t_{3,0}=$ common parts' depletion time,

$t_{0}{ }^{*}=$ the sum of optimal uptime and rework time of the common parts (in stage one),

$t_{1, i} \quad=$ uptime for end product $i$,

$t_{2, i} \quad=$ rework time for end product $i$,

$t_{3, i}=$ depletion time for end product $i$,

$t_{i}^{*}=$ the optimal total uptimes and rework times of the end products (in stage two),

$\pi_{0} \quad=$ the outsourcing portion of the lot size of common parts (in stage 1),

$K_{0} \quad=$ in-house common part's setup cost,

$K_{\pi 0} \quad=$ fixed cost of outsourcing,

$\beta_{1,0}=$ the connecting factor between $K_{\pi 0}$ and $K_{0}$,

$C_{0} \quad=$ in-house common part's unit cost,

$C_{\pi 0}=$ common part's unit outsourcing cost,

$\beta_{2,0}=$ the connecting factor between $C_{\pi 0}$ and $C_{0}$,

$P_{1,0}=$ common part's annual fabrication rate,

$x_{0}=$ common part's random defective rate,

$d_{1,0}=$ defective common parts' production rate (i.e., $d_{1,0}=P_{1,0} x_{0}$ ),

$\theta_{1,0}=$ scrap portion of defective common parts,

$h_{1,0}=$ common part's unit holding cost,

$h_{4,0}=$ safety common part's unit holding cost,

$P_{2,0}=$ annual reworking rate for defective common part's,

$C_{\mathrm{R}, 0}=$ common part's unit rework cost,

$\theta_{2,0}=$ scrap portion of the reworked common parts,

$d_{2,0}=$ scrap common parts' production rate in $t_{2,0}$ (i.e., $d_{2,0}=P_{2,0} \theta_{2,0}$ ),

$C_{\mathrm{S}, 0}=$ unit disposal cost for scrapped common parts,

$\varphi_{0} \quad=$ common part's total scrap portion,

$h_{2,0}=$ unit holding cost for reworked common parts,

$i_{0} \quad=$ the relating ratio for holding cost (e.g., $\left.h_{1,0}=i_{0} C_{0}\right)$,

$\gamma \quad=$ the completion rate of common part compared with the end item,

$S_{0} \quad=$ common part's setup time,

$S_{i} \quad=$ setup time for end product $i$,

$H_{1, i} \quad=$ stock level of end product $i$ when its production process completes,

$H_{i} \quad=$ inventory level of common parts when the production process of item $i$ ends, 


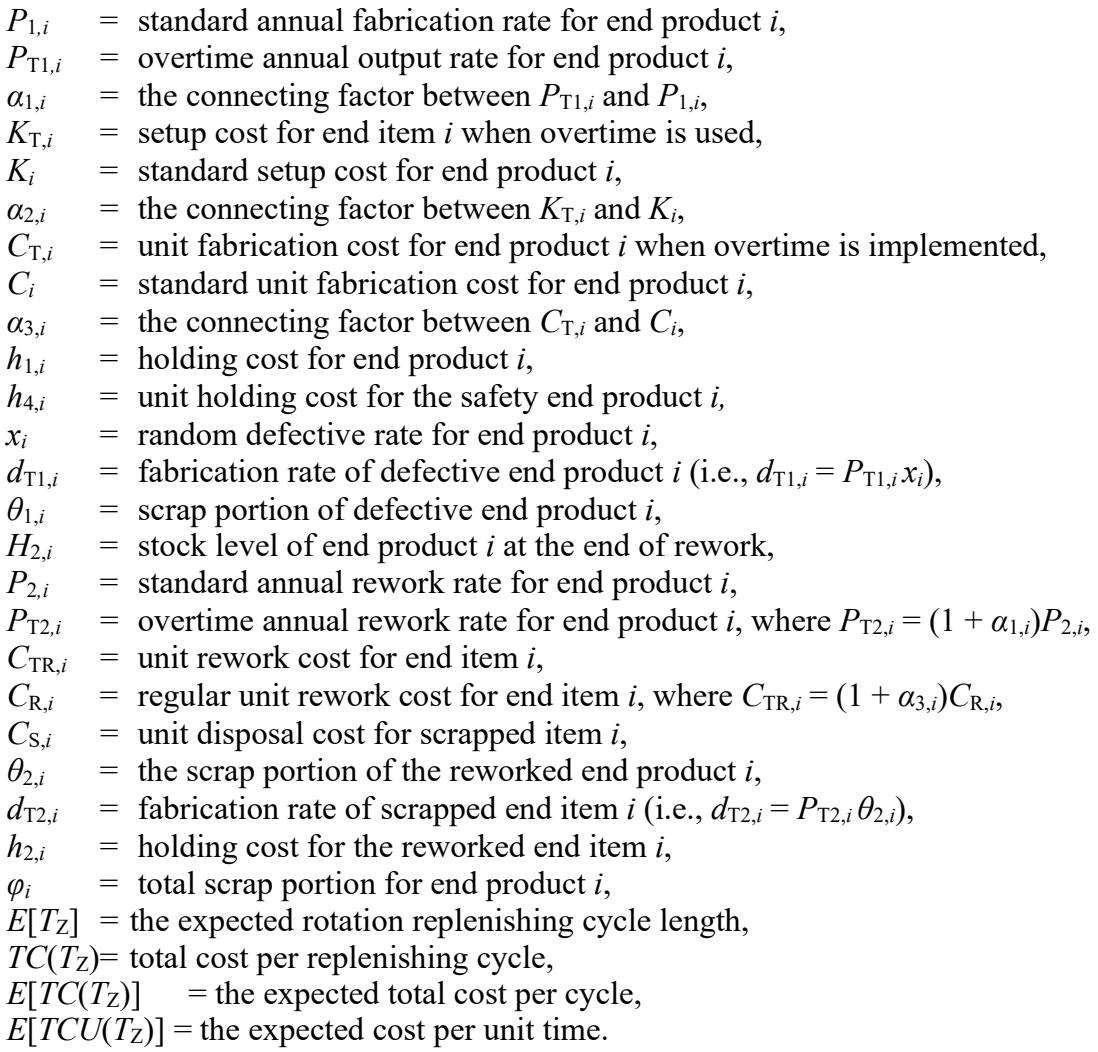

\section{Appendix - B}

The detailed derivations of Eq. (30) are given below.

First, by applying the expected values $E\left[x_{0}\right]$ and $E\left[x_{i}\right]$ (where $i=1,2, \ldots, L$ ) to deal with random defective rates. Then, replacing Eqs. (1) to (28) in $T C\left(T_{\mathrm{Z}}\right)$. Finally, applying $E\left[T C\left(T_{\mathrm{Z}}\right)\right] / E\left[T_{\mathrm{Z}}\right]$ and with extra derivation efforts, we gain the following $E\left[T C U\left(T_{\mathrm{Z}}\right)\right]$ :

$$
\begin{aligned}
& E\left[T C U\left(T_{Z}\right)\right]=\left\{\begin{array}{l}
\frac{\left(1+\beta_{1,0}\right) K_{0}}{T_{Z}}+\left(1+\beta_{2,0}\right) C_{0} \pi_{0} \lambda_{0}+C_{0} \frac{\left(1-\pi_{0}\right) \lambda_{0}}{1-\varphi_{0} E\left[x_{0}\right]}+\frac{K_{0}}{T_{Z}}+C_{R, 0} E\left[x_{0}\right]\left(1-\theta_{1,0}\right)\left[\frac{\left(1-\pi_{0}\right) \lambda_{0}}{1-\varphi_{0} E\left[x_{0}\right]}\right] \\
+C_{S, 0}\left(E\left[x_{0}\right] \varphi_{0}\right)\left[\frac{\left.\left(1-\pi_{0}\right) \lambda_{0}\right]}{1-\varphi_{0} E\left[x_{0}\right]}\right]+\frac{h_{2,0} \lambda_{0}^{2} T_{Z}}{2} \frac{\left(1-\pi_{0}\right)^{2}}{\left(1-\varphi_{0} E\left[x_{0}\right]\right)^{2}}\left[\frac{E\left[x_{0}\right]^{2}\left(1-\theta_{1,0}\right)^{2}}{P_{2,0}}\right] \\
+h_{4,0} \varphi_{0} \lambda_{0} T_{Z}\left[\frac{\left(1-\pi_{0}\right) E\left[x_{0}\right]}{1-\varphi_{0} E\left[x_{0}\right]}\right]+\frac{h_{1,0} \lambda_{0}^{2} T_{Z}}{2} \frac{\left(1-\pi_{0}\right)^{2}}{\left(1-\varphi_{0} E\left[x_{0}\right]\right)^{2}}\left[\frac{1}{P_{1,0}}+\frac{E\left[x_{0}\right]\left(1-\theta_{1,0}\right)\left[2-E\left[x_{0}\right]\left(\varphi_{0}+1\right)\right]}{P_{2,0}}\right]
\end{array}\right\}
\end{aligned}
$$

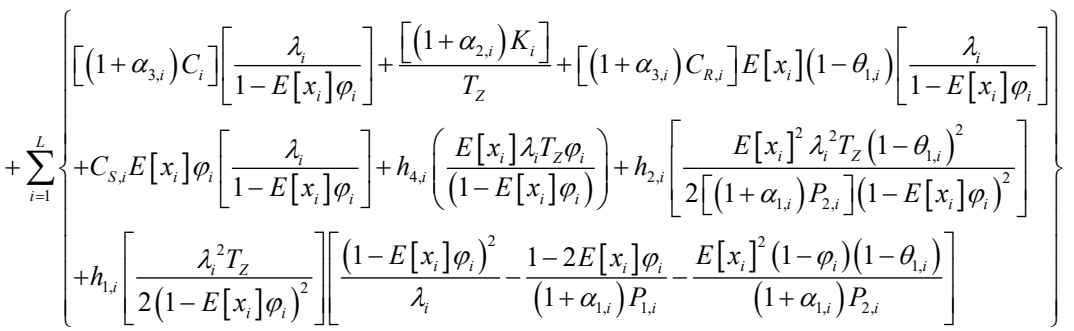

Let $E_{00}, E_{10}, E_{0 j}, E_{0 P}, E_{0 i}, E_{1 i}, E_{2 i}$, and $E_{3 i}$ represent the following: 


$$
\begin{aligned}
& E_{00}=\frac{1}{\left(1-\varphi_{0} E\left[x_{0}\right]\right)} ; E_{10}=\frac{E\left[x_{0}\right]}{\left(1-\varphi_{0} E\left[x_{0}\right]\right)} ; E_{0 j}=\frac{1}{\left(1-\varphi_{j} E\left[x_{j}\right]\right)} \text { for } j=1, \ldots, i \\
& E_{0 P}=\left[\frac{1}{P_{1,0}}+\frac{E\left[x_{0}\right]\left(1-\theta_{1,0}\right)\left[2-E\left[x_{0}\right]\left(\varphi_{0}+1\right)\right]}{P_{2,0}}\right] . \\
& E_{0 i}=\frac{1}{\left(1-\varphi_{i} E\left[x_{i}\right]\right)} ; E_{1 i}=\frac{E\left[x_{i}\right]}{\left(1-\varphi_{i} E\left[x_{i}\right]\right)} ; E_{2 i}=\left[\frac{1}{\left[\left(1+\alpha_{1, i}\right) P_{1, i}\right]}+\frac{E\left[x_{i}\right]\left(1-\theta_{1, i}\right)}{\left[\left(1+\alpha_{1, i}\right) P_{2, i}\right]}\right] ; \\
& E_{3 i}=\left[\frac{\left(1-E\left[x_{i}\right] \varphi_{i}\right)^{2}}{\lambda_{i}}-\frac{1-2 E\left[x_{i}\right] \varphi_{i}}{\left(1+\alpha_{1, i}\right) P_{1, i}}-\frac{E\left[x_{i}\right]^{2}\left(1-\varphi_{i}\right)\left(1-\theta_{1, i}\right)}{\left(1+\alpha_{1, i}\right) P_{2, i}}\right] \text { for } i=1, \ldots, L .
\end{aligned}
$$

Substitute Eqs. (B-2) and (B-3) in Eq. (B-1), we find $E\left[T C U\left(T_{\mathrm{Z}}\right)\right]$ as follows:

$$
\begin{aligned}
& E\left[T C U\left(T_{Z}\right)\right]=\left\{\begin{array}{l}
\frac{\left(1+\beta_{1,0}\right) K_{0}}{T_{Z}}+\left(1+\beta_{2,0}\right) C_{0} \pi_{0} \lambda_{0}+C_{0}\left(1-\pi_{0}\right) \lambda_{0} E_{00}+\frac{K_{0}}{T_{Z}}+C_{R, 0}\left(1-\theta_{1,0}\right)\left(1-\pi_{0}\right) \lambda_{0} E_{10} \\
+C_{S, 0}\left(1-\pi_{0}\right) \varphi_{0} \lambda_{0} E_{10}+\frac{h_{2,0} \lambda_{0}^{2}\left(1-\theta_{1,0}\right)^{2}\left(1-\pi_{0}\right)^{2}}{2 P_{2,0}}\left(E_{10}\right)^{2} T_{Z}+\frac{h_{1,0} \lambda_{0}^{2} T_{Z}}{2}\left(1-\pi_{0}\right)^{2}\left(E_{00}\right)^{2} E_{0 P} \\
+h_{4,0}\left(1-\pi_{0}\right) \varphi_{0} \lambda_{0} E_{10} T_{Z}+h_{1,0} \sum_{i=1}^{L}\left\{\frac{\lambda_{i}^{2} T_{Z}\left(E_{0 i}\right)^{2}}{2\left[\left(1+\alpha_{1, i}\right) P_{1, i}\right]}+\left(\sum_{i=1}^{L}\left[\lambda_{i} T_{Z} E_{0 i}\right]-\sum_{j=1}^{i}\left[\lambda_{j} T_{Z} E_{0 j}\right]\right) \lambda_{i} E_{0 i} E_{2 i}\right\}
\end{array}\right\} \\
&+\sum_{i=1}^{L}\left\{\begin{array}{l}
{\left[\left(1+\alpha_{3, i}\right) C_{i}\right] \lambda_{i} E_{0 i}+\frac{\left[\left(1+\alpha_{2, i}\right) K_{i}\right]}{T_{Z}}+\left[\left(1+\alpha_{3, i}\right) C_{R, i}\right]\left(1-\theta_{1, i}\right) \lambda_{i} E_{1 i}} \\
+C_{S, i} \varphi_{i} \lambda_{i} E_{1 i}+h_{4, i} \varphi_{i} \lambda_{i} E_{1 i} T_{Z}+h_{2, i} \frac{T_{Z}\left(1-\theta_{1, i}\right)^{2}}{2\left[\left(1+\alpha_{1, i}\right) P_{2, i}\right]}\left(\lambda_{i} E_{1 i}\right)^{2}+h_{1, i}\left[\frac{T_{Z}}{2}\right]\left(\lambda_{i} E_{0 i}\right)^{2} E_{3 i}
\end{array}\right\}
\end{aligned}
$$

Appendix - C

\section{Table C-1}

Assumption of variables' values of a single-stage scheme of the same problem (1/2)

\begin{tabular}{cccccccc}
\hline Product $i$ & $P_{1, i}$ & $C_{i}$ & $K_{i}$ & $i$ & $h_{1, i}$ & $\lambda_{i}$ & $h_{4, i}$ \\
\hline 1 & 58000 & $\$ 80$ & $\$ 17000$ & 0.2 & $\$ 16$ & 3000 & $\$ 16$ \\
2 & 59000 & $\$ 90$ & $\$ 17500$ & 0.2 & $\$ 18$ & 3200 & $\$ 18$ \\
3 & 60000 & $\$ 100$ & $\$ 18000$ & 0.2 & $\$ 20$ & 3400 & $\$ 20$ \\
4 & 61000 & $\$ 110$ & $\$ 18500$ & 0.2 & $\$ 22$ & 3600 & $\$ 22$ \\
5 & 62000 & $\$ 120$ & $\$ 19000$ & 0.2 & $\$ 24$ & 3800 & $\$ 24$ \\
\hline
\end{tabular}

\section{Table C-2}

Assumption of variables' values of a single-stage scheme of the same problem (2/2)

\begin{tabular}{ccccccccc}
\hline Product $i$ & $x_{i}$ & $C_{\mathrm{S}, i}$ & $\theta_{1, i}$ & $C_{\mathrm{R}, i}$ & $P_{2, i}$ & $h_{2, i}$ & $\theta_{2, i}$ & $\varphi_{i}$ \\
\hline 1 & $5 \%$ & $\$ 20$ & 0.094 & $\$ 50$ & 46400 & $\$ 16$ & 0.094 & 0.18 \\
2 & $10 \%$ & $\$ 25$ & 0.146 & $\$ 55$ & 47200 & $\$ 18$ & 0.146 & 0.27 \\
3 & $15 \%$ & $\$ 30$ & 0.200 & $\$ 60$ & 48000 & $\$ 20$ & 0.200 & 0.36 \\
4 & $20 \%$ & $\$ 35$ & 0.258 & $\$ 65$ & 48800 & $\$ 22$ & 0.258 & 0.45 \\
5 & $25 \%$ & $\$ 40$ & 0.322 & $\$ 70$ & 49600 & $\$ 24$ & 0.322 & 0.54 \\
\hline
\end{tabular}




\section{Appendix - D}

\section{Table D-1}

The impact of changes in outsourcing factor $\pi_{0}$ on various system parameters

\begin{tabular}{|c|c|c|c|c|c|c|c|c|c|c|c|c|c|}
\hline$\pi_{0}$ & $\begin{array}{l}t_{1,0} \\
(\mathrm{~A})\end{array}$ & $\begin{array}{l}t_{2,0} \\
\text { (B) }\end{array}$ & $\begin{array}{c}t_{0}{ }^{*} \\
(\mathrm{~A})+(\mathrm{B})\end{array}$ & $\begin{array}{c}t_{0}^{*} \\
\text { decline } \\
\%\end{array}$ & $\begin{array}{l}\text { Machine } \\
\text { Utiliza- } \\
\text { tion (C) }\end{array}$ & $\begin{array}{c}(\mathrm{C}) \\
\text { decline } \\
\%\end{array}$ & $\begin{array}{c}\mathrm{E}\left[T C U\left(T_{\mathrm{z}}{ }^{*}\right)\right] \\
\text { (D) }\end{array}$ & $\begin{array}{c}\text { (D) } \\
\text { increase } \\
\%\end{array}$ & $T_{\mathrm{z}}{ }^{*}$ & $\begin{array}{c}\text { Additional } \\
\text { cost due to } \\
\text { outsourcing } \\
\text { (E) }\end{array}$ & $\begin{array}{c}(\mathrm{E}) /(\mathrm{D}) \\
\%\end{array}$ & $\begin{array}{l}\text { Common } \\
\text { parts' } \\
\text { quality } \\
\text { cost }(\mathrm{F}) \\
\end{array}$ & $\begin{array}{c}(\mathrm{F}) /(\mathrm{D}) \\
\%\end{array}$ \\
\hline 0.00 & 0.0809 & 0.0012 & 0.0821 & - & 0.2500 & - & $\$ 2,312,415$ & - & 0.5574 & $\$ 0$ & $0.00 \%$ & $\$ 6,176$ & $0.27 \%$ \\
\hline 0.05 & 0.0787 & 0.0012 & 0.0799 & $-2.7 \%$ & 0.2426 & $-3.0 \%$ & $\$ 2,329,974$ & $0.76 \%$ & 0.5705 & $\$ 53,206$ & $2.28 \%$ & $\$ 5,867$ & $0.25 \%$ \\
\hline 0.10 & 0.0748 & 0.0011 & 0.0759 & $-7.6 \%$ & 0.2352 & $-5.9 \%$ & $\$ 2,343,035$ & $1.32 \%$ & 0.5720 & $\$ 101,932$ & $4.35 \%$ & $\$ 5,558$ & $0.24 \%$ \\
\hline 0.15 & 0.0708 & 0.0011 & 0.0719 & $-12.4 \%$ & 0.2279 & $-8.8 \%$ & $\$ 2,356,125$ & $1.89 \%$ & 0.5733 & $\$ 150,658$ & $6.39 \%$ & $\$ 5,249$ & $0.22 \%$ \\
\hline 0.20 & 0.0668 & 0.0010 & 0.0678 & $-17.4 \%$ & 0.2205 & $-11.8 \%$ & $\$ 2,369,243$ & $2.46 \%$ & 0.5746 & $\$ 199,385$ & $8.42 \%$ & $\$ 4,941$ & $0.21 \%$ \\
\hline 0.25 & 0.0627 & 0.0009 & 0.0636 & $-22.5 \%$ & 0.2131 & $-14.8 \%$ & $\$ 2,382,389$ & $3.03 \%$ & 0.5758 & $\$ 248,112$ & $10.41 \%$ & $\$ 4,632$ & $0.19 \%$ \\
\hline 0.30 & 0.0587 & 0.0009 & 0.0596 & $-27.4 \%$ & 0.2057 & $-17.7 \%$ & $\$ 2,395,565$ & $3.60 \%$ & 0.5770 & $\$ 296,840$ & $12.39 \%$ & $\$ 4,323$ & $0.18 \%$ \\
\hline 0.35 & 0.0546 & 0.0008 & 0.0554 & $-32.5 \%$ & 0.1984 & $-20.6 \%$ & $\$ 2,408,771$ & $4.17 \%$ & 0.5781 & $\$ 345,569$ & $14.35 \%$ & $\$ 4,014$ & $0.17 \%$ \\
\hline 0.40 & 0.0505 & 0.0008 & 0.0513 & $-37.5 \%$ & 0.1910 & $-23.6 \%$ & $\$ 2,422,005$ & $4.74 \%$ & 0.5791 & $\$ 394,298$ & $16.28 \%$ & $\$ 3,705$ & $0.15 \%$ \\
\hline 0.45 & 0.0463 & 0.0007 & 0.0470 & $-42.8 \%$ & 0.1836 & $-26.6 \%$ & $\$ 2,435,269$ & $5.31 \%$ & 0.5800 & $\$ 443,028$ & $18.19 \%$ & $\$ 3,396$ & $0.14 \%$ \\
\hline 0.50 & 0.0422 & 0.0006 & 0.0428 & $-47.9 \%$ & 0.1763 & $-29.5 \%$ & $\$ 2,448,563$ & $5.89 \%$ & 0.5809 & $\$ 491,758$ & $20.08 \%$ & $\$ 3,088$ & $0.13 \%$ \\
\hline 0.55 & 0.0380 & 0.0006 & 0.0386 & $-53.0 \%$ & 0.1689 & $-32.4 \%$ & $\$ 2,461,887$ & $6.46 \%$ & 0.5817 & $\$ 540,489$ & $21.95 \%$ & $\$ 2,779$ & $0.11 \%$ \\
\hline 0.60 & 0.0338 & 0.0005 & 0.0343 & $-58.2 \%$ & 0.1615 & $-35.4 \%$ & $\$ 2,475,241$ & $7.04 \%$ & 0.5824 & $\$ 589,220$ & $23.80 \%$ & $\$ 2,470$ & $0.10 \%$ \\
\hline 0.65 & 0.0296 & 0.0004 & 0.0300 & $-63.5 \%$ & 0.1542 & $-38.3 \%$ & $\$ 2,488,624$ & $7.62 \%$ & 0.5830 & $\$ 637,952$ & $25.63 \%$ & $\$ 2,161$ & $0.09 \%$ \\
\hline 0.70 & 0.0254 & 0.0004 & 0.0258 & $-68.6 \%$ & 0.1468 & $-41.3 \%$ & $\$ 2,502,038$ & $8.20 \%$ & 0.5835 & $\$ 686,685$ & $27.45 \%$ & $\$ 1,853$ & $0.07 \%$ \\
\hline 0.75 & 0.0212 & 0.0003 & 0.0215 & $-73.8 \%$ & 0.1394 & $-44.2 \%$ & $\$ 2,515,482$ & $8.78 \%$ & 0.5840 & $\$ 735,418$ & $29.24 \%$ & $\$ 1,544$ & $0.06 \%$ \\
\hline 0.80 & 0.0170 & 0.0003 & 0.0173 & $-78.9 \%$ & & $-47.2 \%$ & $\$ 2,528,9$ & $9.36 \%$ & 0.5844 & $\$ 784,1$ & $31.01 \%$ & $\$ 1,235$ & $0.05 \%$ \\
\hline 0.85 & 0.0127 & 0.0002 & 0.0129 & & & & & $9.95 \%$ & & $\$ 832,887$ & $32.76 \%$ & & $0.04 \%$ \\
\hline 0.90 & 0.0085 & 0.0001 & 0.0086 & $-89.5 \%$ & & $-53.1 \%$ & $\$ 2,555,997$ & $10.53 \%$ & 0.5849 & $\$ 881,622$ & $34.49 \%$ & & $0.02 \%$ \\
\hline 0.95 & 0.0042 & 0.0001 & 0.0043 & $-94.8 \%$ & 0.1100 & $-56.0 \%$ & $\$ 2,569,563$ & $11.12 \%$ & 0.5850 & $\$ 930,358$ & $36.21 \%$ & $\$ 309$ & $0.01 \%$ \\
\hline 1.00 & 0.0000 & 0.0000 & 0.0000 & $-100.0 \%$ & 0.1026 & $-59.0 \%$ & $\$ 2,568,108$ & $11.06 \%$ & 0.5444 & $\$ 979,420$ & $38.14 \%$ & $\$ 0$ & $0.00 \%$ \\
\hline
\end{tabular}

Table D-2

The impact of changes in overtime factor $\alpha_{1,0}$ on various system parameters

\begin{tabular}{|c|c|c|c|c|c|c|c|c|c|c|c|c|c|c|c|}
\hline$\alpha_{1,0}$ & $T_{\mathrm{Z}}{ }^{*}$ & $\alpha_{3,0}$ & $\alpha_{2,0}$ & $\begin{array}{l}\text { Sum of } \\
t_{1, i}(\mathrm{~A})\end{array}$ & $\begin{array}{l}\text { Sum of } \\
t_{2, i}(\mathrm{~B})\end{array}$ & $\begin{array}{l}t_{t_{\mathrm{i}}^{*}} \\
(\mathrm{~A})^{+} \\
\text {(B) }\end{array}$ & $\begin{array}{c}t_{\mathrm{i}}{ }^{*} \\
\text { decline } \\
\%\end{array}$ & $\begin{array}{l}\text { Machine } \\
\text { Utiliza- } \\
\text { tion }(\mathrm{C})\end{array}$ & $\begin{array}{l}\text { C) } \% \\
\text { ecline }\end{array}$ & $\begin{array}{l}\text { Extra cost } \\
\text { due to } \\
\text { overtime } \\
\text { (D) }\end{array}$ & $\begin{array}{c}(\mathrm{D}) /(\mathrm{F}) \\
\%\end{array}$ & $\begin{array}{l}\text { End } \\
\text { products' } \\
\text { quality } \\
\text { cost }(\mathrm{E})\end{array}$ & $\begin{array}{c}(\mathrm{E}) /(\mathrm{F}) \\
\%\end{array}$ & $\begin{array}{c}\mathrm{E}\left[T C U\left(T_{\mathrm{Z}}{ }^{*}\right)\right] \\
(\mathrm{F})\end{array}$ & $\begin{array}{l}(\mathrm{F}) \% \\
\text { increase }\end{array}$ \\
\hline 0 & 5541 & 0.00 & 00 & 801 & .0052 & 0853 & - & & - & $\$ 0$ & & $\$ 75,755$ & & & - \\
\hline 0.1 & 594 & 5 & & & & 0783 & & & & & & & & & \\
\hline & & 10 & & & & & & & & & & & & & \\
\hline 0.3 & 5694 & 15 & 06 & & & 0674 & & & & & $7.40 \%$ & 22 & & & $\%$ \\
\hline 0.4 & 743 & 20 & & & & & & & & & & & & & \\
\hline 0.5 & 5791 & 0.25 & 10 & 0558 & 0.00 & 0.0594 & -30 . & & & 1,504 & $11.75 \%$ & $\$ 83,033$ & $3.43 \%$ & & $26 \%$ \\
\hline 0.6 & 5838 & 30 & & & & & & & & & & & & & \\
\hline 0.7 & 5884 & 0.35 & 14 & & & 0.0532 & -37 & & & & & & & & \\
\hline 0.8 & 5930 & 40 & 16 & & & & & & & & & & & & \\
\hline 0.9 & 0.5975 & 0.45 & 18 & 0454 & 0.0029 & 0.0483 & & & & & & & & & \\
\hline 1.0 & 6020 & 50 & 20 & & & .0463 & $\%$ & & & & & & & & \\
\hline 1.1 & 0.6064 & 55 & & & & 0.0444 & & & & & & & & & \\
\hline 1.2 & 0.6107 & 0.60 & 24 & & 0.0026 & 0.0427 & $-49.9 \%$ & & & & $24.18 \%$ & $\$ 93,227$ & $3.31 \%$ & & \\
\hline 1.3 & 0.6151 & 0.65 & & & & 0.0411 & & & & & & $\$ 94,683$ & & & \\
\hline 1.4 & 0.6193 & 70 & 28 & 373 & 0.0024 & 0.0397 & -53.5 & & & 120 & $27.11 \%$ & $\$ 96,139$ & $3.28 \%$ & & \\
\hline 1.5 & 0.6236 & 75 & & & & .0383 & & & & & & & & & \\
\hline 1.6 & 0.6278 & 0.80 & 32 & & & 0.0372 & -56.4 & & & & $29.82 \%$ & $\$ 99,052$ & $3.25 \%$ & & $42.45 \%$ \\
\hline 1.7 & 0.6320 & 0.85 & & & & .0360 & & & & $\$ 964,982$ & $31.10 \%$ & $\$ 100,508$ & $3.24 \%$ & & $45.10 \%$ \\
\hline 1.8 & 0.6361 & 0.90 & 36 & & & & & & & & & & & & $47.76 \%$ \\
\hline 1.9 & .6402 & 0.95 & & & & .0340 & & & & & & $\$ 103,421$ & & & $50.41 \%$ \\
\hline 2.0 & 0.6443 & 1.00 & 0.40 & 0.0310 & 0.0020 & 0.0330 & $-61.3 \%$ & 0.1397 & $-42.3 \%$ & $\$ 1,134,698$ & $34.67 \%$ & $\$ 104,877$ & $3.20 \%$ & $\$ 3,273,029$ & $53.06 \%$ \\
\hline
\end{tabular}

